\title{
Age of Martian Channels
}

\author{
Michael C. Malin ${ }^{1}$ \\ Division of Geological and Planetary Sciences, California Institute of Technology, Pasadena, California 91125
}

\begin{abstract}
The ages of large martian channels have been studied by determining the relative abundances of craters superimposed on channels and adjacent terrains and by examining superposition relationships between channels and plains and mantle materials. The channels are extremely old, are spatially confined and temporally related to the ancient cratered terrain, and in many cases are related to the as yet poorly understood genetic processes of fretting and chaos formation. No evidence is found for recent channel activity.
\end{abstract}

\section{INTRODUCTION}

Of landforms revealed by the Mariner 9 spacecraft during its global reconnaissance of Mars in 1971 and 1972, some of the most dramatic and controversial remain the large, often sinuous channels so reminiscent of terrestrial river channels.

In the years since the completion of the Mariner 9 mission, strong differences have developed within the scientific community concerning the mode of channel formation. Low-resolution images foster ambiguous interpretations of morphologic features, often allowing the same channel to be cited as a type example' by authors presenting opposed points of view. Unfortunately, higher-resolution photography, when available, often provides as much confusion as clarification. Furthermore, each martian channel has individual characteristics, so that discussions tend to revolve around unique, possibly anomalous, examples. The general categorization scheme developed by Sharp and Malin [1975] will be used to limit the discussion in this paper to a few specific types of channels. Sharp and Malin [1975] discuss the difficulties in developing a purely nongenetic classification system for martian channels and present a scheme with strong genetic overtones. The channels studied here are those which appear to be formed by the action of external processes on the martian surface, although the considerations of this paper are essentially independent of the mechanism of channel genesis.

The focus of this paper is upon the important question of channel age. Initially, it was believed that channels were extremely young because of their fresh appearance and the paucity of superimposed impact craters [cf. Masursky, 1973; Hartmann, 1973]. Early crater counts seemed to indicate ages similar to those of the Tharsis volcanoes and south polar layered deposits, suggesting that Mars had undergone recent geological and, presumably, climatological changes. Estimates of absolute age, based on an impact flux enhanced by as much as a factor of 25 relative to the moon, ranged from tens of millions to hundreds of millions of years. Current interpretation, based on the recognition of more craters and on the reduction of the Mars-to-moon enhancement factor, would increase these ages by an order of magnitude [Soderblom et al., 1974].

This paper draws upon new crater counts and superposition criteria to establish age relationships between martian channels and other surface features. Implications of these relative

\footnotetext{
${ }^{1}$ Now at Planetology and Oceanography Section, Jet Propulsion Laboratory, California Institute of Technology, Pasadena, California 91103.

Copyright (C) 1976 by the American Geophysical Union.
}

ages and a possible absolute time scale are discussed in a separate section.

\section{General Properties of Channels}

The general types of channels considered herein are illustrated in Figure 1 and are defined by Sharp and Malin [1975] as follows.

Outflow channels. These are mostly large features that start full-born from localized sources. They are broadest and deepest at the head and decrease in size distally. Some appear to be scoured and display features suggestive of massive catastrophic flooding.

Runoff channels. Such channels typically start small and increase in size and depth distally. The headwaters usually have tributary branches. Configurational control by crustal structures can be strong.

Fretted channels. These are steep-walled features with wide smooth concordant floors. Planimetric configuration can be complex, irregularly indented walls, integrated craters, and control by linear crusted structures, presumably fractures, often being evident. Isolated buttelike or mesalike outliers are common, and extensive lateral integration of adjacent channels has occurred locally.

The large martian channels studied in this work are hundreds of kilometers long, several kilometers wide, and as much as a kilometer deep. Their geographic distribution is shown in Figure 2 and given in Table 1 . Two major characteristics are apparent in their geographical and geological relationships: (1) with the exception of the Elysium channels, all large channels lie within the heavily cratered part of Mars, and (2) many of the channels appear associated with margins of the heavily cratered terrains. In addition, data from Sagan et al. [1973, Figure 1] suggest that channels are most abundant in, if not restricted to, temperate and tropical latitudes. Runoff and outflow channels seem to head generally in areas of rough, irregular topography. In particular, outflow channel source areas are principally areas of chaotic terrain [e.g., Sharp. 1973] and irregular regions of low, hummocky relief interpreted as regions of lithospheric seepage [Sharp and Malin, 1975]. Fretted channels show no evidence of specific source regions, but some appear to head in craters or in features at least superficially resembling craters associated with modified chaotic terrain.

The Elysium channels are important exceptions to the above general considerations. First, they are the only large channels found outside the heavily cratered regions of Mars. Second, the long, narrow, sinuous channels head in broad, deep, elongate depressions interpreted by Sharp and Malin [1975] as volcano/tectonic in origin. Third, the cross-sectional relief of 


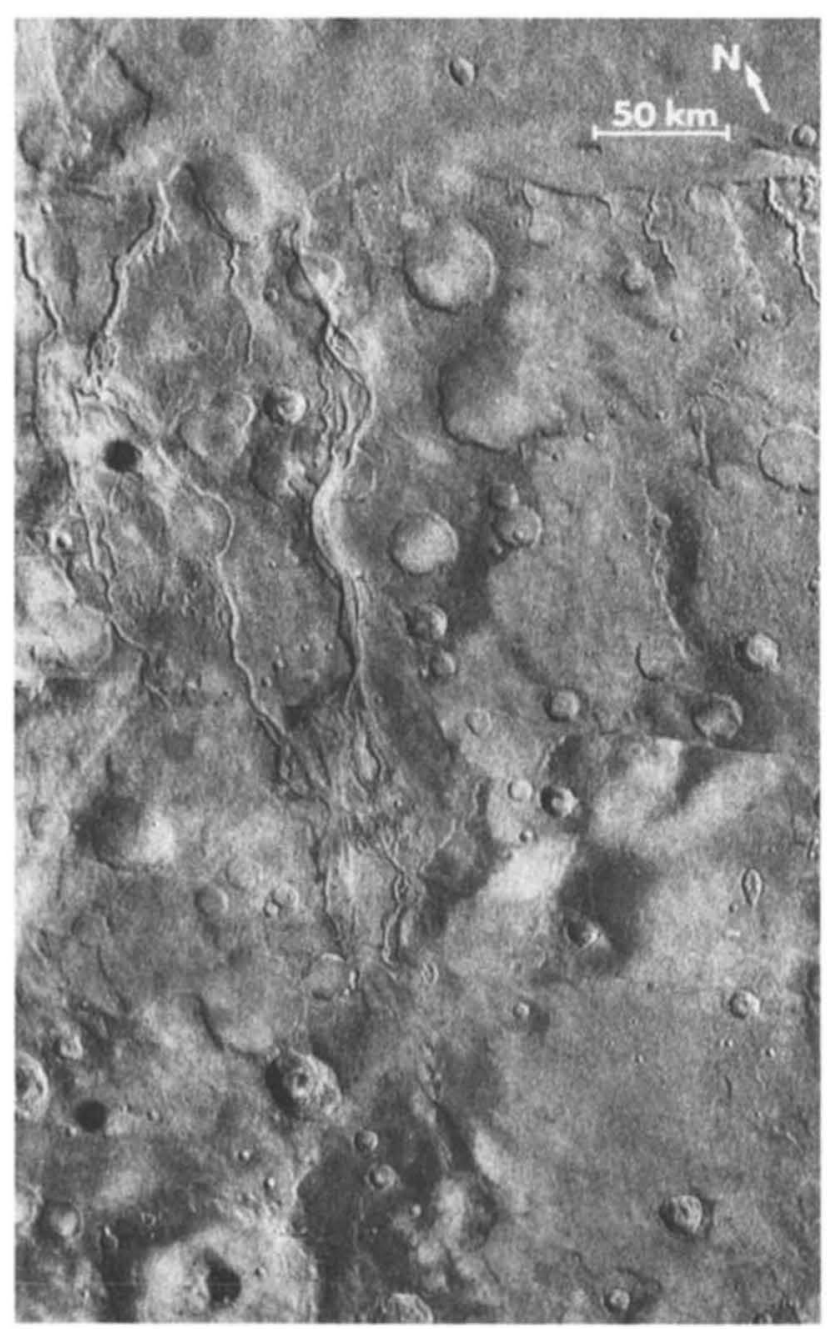

Fig. $1 a$

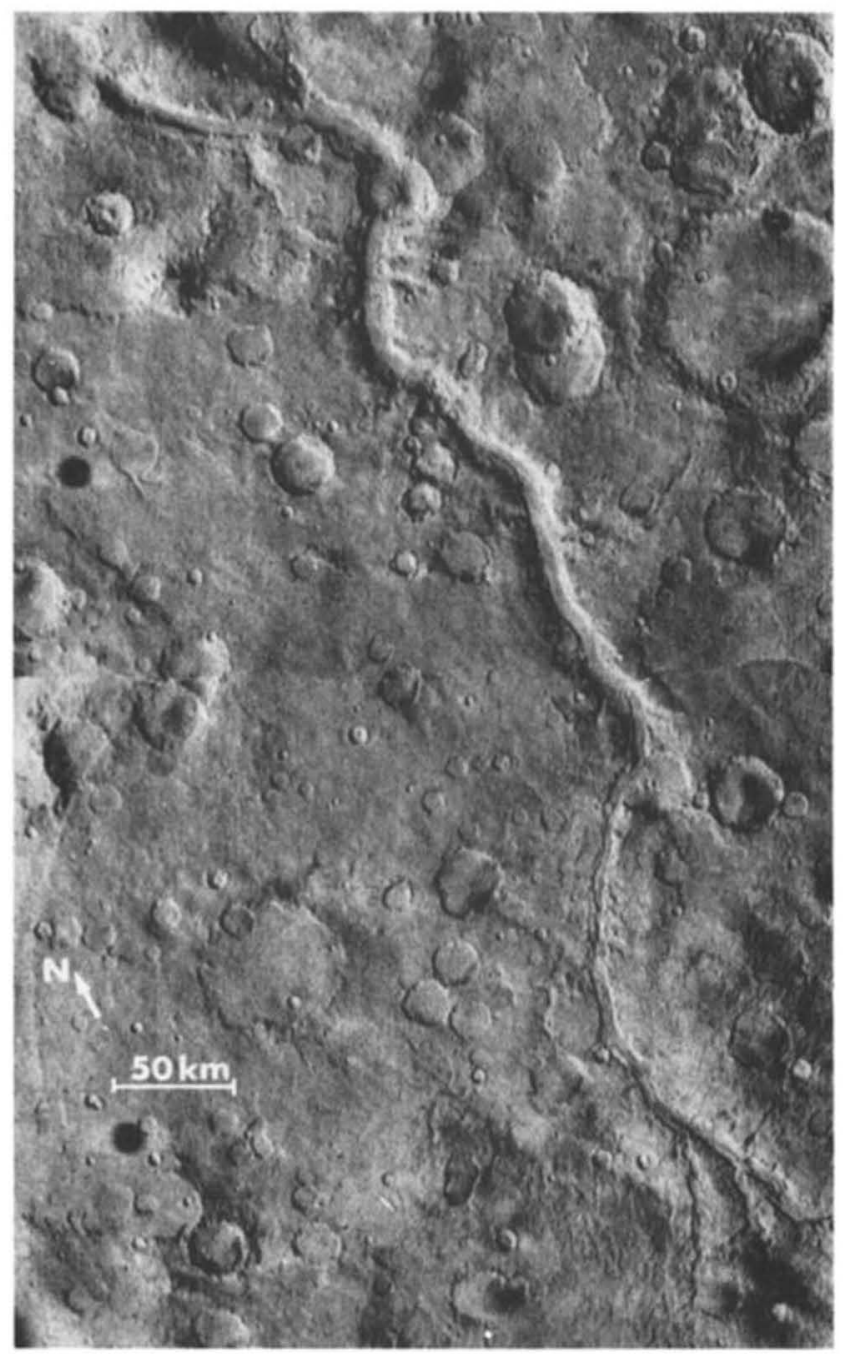

Fig. $1 b$

Fig. 1. Examples of exogenic channels [after Sharp and Malin, 1975]. (a) Outflow channel. A frame mosaic of Mangala Vallis $\left(350 \mathrm{~km}\right.$ long, $10 \mathrm{~km}$ wide) located $151^{\circ} \mathrm{W}, 5^{\circ} \mathrm{S}$ (DAS 6822728,6822792$)$. (b) Runoff channel. Ma'adim Vallis (>700 $\mathrm{km}$ long, $15 \mathrm{~km}$ wide) located $182^{\circ} \mathrm{W}, 21^{\circ} \mathrm{S}$ (DAS 6606708, 6606778). A frame mosaic taken from $1700-\mathrm{km}$ altitude. (c) Fretted channel. Unnamed channel in Deuteronilus $\left(750 \mathrm{~km}\right.$ long, $20 \mathrm{~km}$ wide) located at $343^{\circ} \mathrm{W}, 36^{\circ} \mathrm{N}$ (DAS 9378149 , 9378289).

the channels is markedly subdued. They are included in this study to illuminate limitations in analysis of channel age relationships.

\section{Craters Superimposed on Channels}

The classical technique for determining relative age relationships between various landforms on extraterrestrial planetary surfaces involves the determination of the number of craters formed upon such surfaces. The application of this procedure in its simplest form implies that the greater the number of craters, the older the surface. It therefore assumes that the production of surfaces and the influx of objects are timedependent phenomena. It also assumes that spatial variations, if they exist, can somehow be distinguished.

This simple application becomes much more complicated when erosional processes are considered. While it seems reasonable to assume that the impact process is time dependent and acts isotropically on all regions of a planet, degradational processes greatly confuse the deciphering of the impact history. In this case the most important point is that a crater size range exists which (1) is statistically meaningful and (2) has not reached equilibrium with erosional processes.

Since geologic provinces encompass finite areas, it is often difficult to find enough craters of the desired size to insure interpretative reliability. Error bars on crater counts can quantify a number of variable parameters but most frequently refer to the discriminability of craters of a given size near the limit of resolution (what is the probability that all the craters in the given area have been counted?) and the statistically random property of the extraplanetary source (what is the probability of a given area containing a specific number of craters of a certain size?). The former process is extremely difficult to assess, because it is a complicated function of scene contrast, optics resolution, image motion, and a whole catalog of problems associated with the generation of the image. The latter is much more easily derived, if one assumes the process of impacts to really be random. In that case, crater counts become simply another type of counting experiment and are treatable by using Poisson statistics. Thus a somewhat overestimated standard deviation error bar ( 1 sigma) is the square root of the total number counted. 


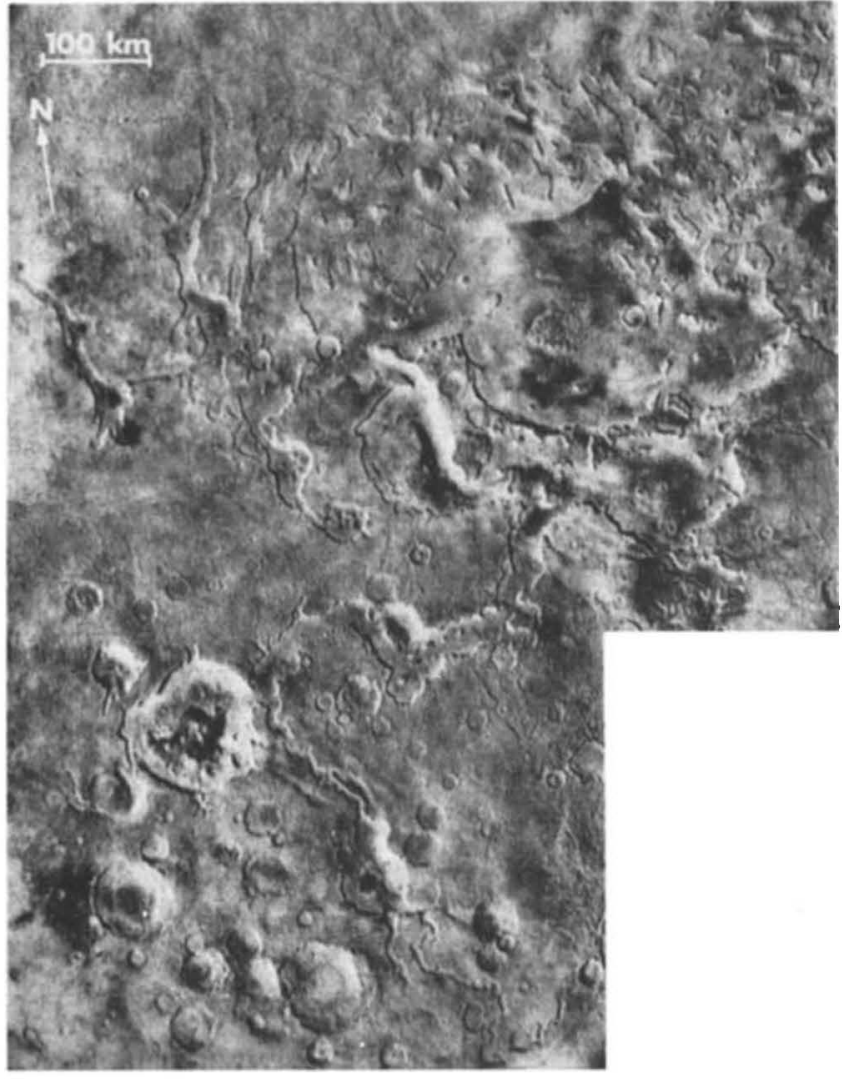

Fig. $1 c$

Three ways have commonly been used to deal with this problem. The first is to work with craters in a well-populated size range, usually those of the order of $0.1-1.0 \mathrm{~km}$ in diameter. This is not usually satisfactory on Mars because the resolution of the Mariner 9 cameras is in this range and because craters of this dimension may be in equilibrium with erosional processes. The second method sums all craters of larger sizes on many small areas and divides by the sum of the areas. If the areas have had a uniform history, there should be no inherent statistical problems, and this is the method most frequently used in martian studies [Hartmann, 1974]. Unfortunately, processes on Mars are known to be nonuniform, and this method therefore yields an average more youthful than the greatest age but older than the youngest. In addition, the youngest ages thus acquired may reflect not the genetic age of formation of the major topographic feature but the time when the surface of this landscape underwent environmentally controlled degradation. The final method is to accept the large errors associated with small populations and to compare the study areas to nearby locations to reduce the possibility of regional variations, to reduce any systematic errors in the counting technique, and to reduce the effects of 'contamination' by secondary craters. In this last case the probability of a swarm of secondaries landing on a small, isolated area and not on the surrounding terrain is very low. Thus by comparing immediately adjacent surfaces and by scrutinizing closely to identify suspicious clusters of craters the effects of secondary cratering can be greatly reduced. This method has been demonstrably successful on the moon [Malin, 1974] in acquiring relative age relationships.

Hartmann [1974] has written the most recent and extensive analysis of martian channel ages. He utilizes two independent crater count methods. At Mangala channel he notes that only one crater as large as $2.5 \mathrm{~km}$ in diameter is seen in five highresolution photographs with a total channel area of $2200 \mathrm{~km}^{2}$. Estimating that one such crater is formed on Mars every $1-8 \times$ $10^{4}$ years on the basis of a Mars/lunar flux enhancement ratio which ranges from $8: 1$ for the more youthful age to $1: 1$ for the older age, he determines that there is a significant probability that Mangala is of the order of $6 \times 10^{8}$ to $5 \times 10^{9}$ years old. In the same work, to avoid 'statistics of one,' Hartmann sums 31 craters (diameter of $>0.25 \mathrm{~km}$ ) visible on five unspecified

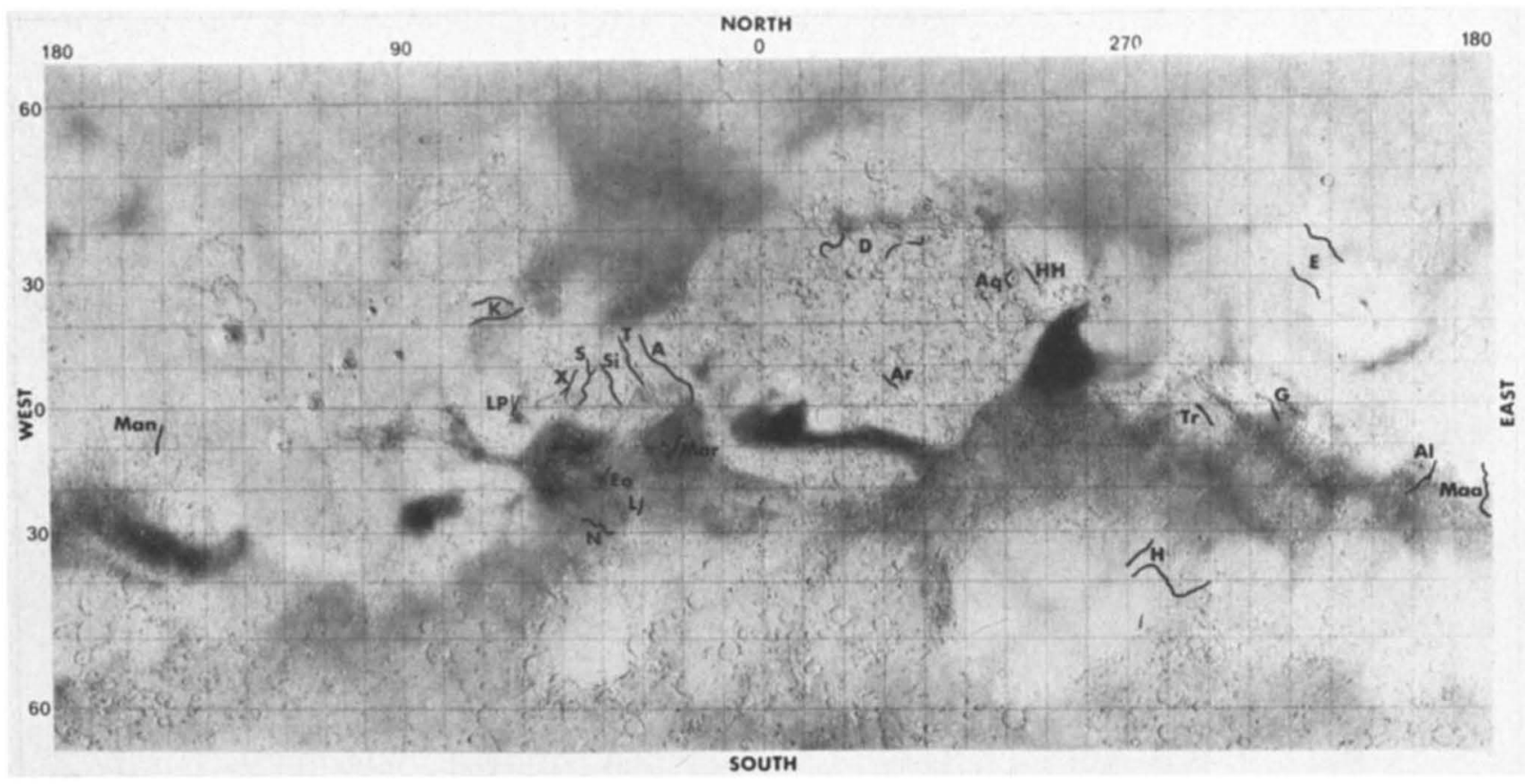

Fig. 2. Airbrush shaded relief map of Mars. Mercator projection showing location of largest martian channels (for key to abbreviations, see Table 1). Large channels are named; unnamed channels are usually shorter and narrower. Map prepared by U.S. Geological Survey and Lowell Observatory, Flagstaff, Arizona. 
TABLE 1. Large Martian Channels

\begin{tabular}{|c|c|c|c|}
\hline $\begin{array}{c}\text { Channel Name } \\
\text { or Region }\end{array}$ & $\begin{array}{l}\text { Latitude, } \\
\text { deg }\end{array}$ & $\begin{array}{l}\text { Longitude, } \\
\text { deg }\end{array}$ & Type* \\
\hline Deuteronilus (D) & $36 \mathrm{~N}$ & $343 \mathrm{~W}$ & fretted \\
\hline Deuteronilus (D) & $36 \mathrm{~N}$ & $330 \mathrm{~W}$ & fretted \\
\hline Elysium (E) & $37 \mathrm{~N}$ & $220 \mathrm{~W}$ & outflow (?) \\
\hline Kasai (K) & $27 \mathrm{~N}$ & $69 \mathrm{~W}$ & modified fretted \\
\hline KASAI (K) & $23 \mathrm{~N}$ & $67 \mathrm{~W}$ & modified fretted \\
\hline Lunae Planum (LP) & $2 \mathrm{~N}$ & $60 \mathrm{~W}$ & outflow \\
\hline Xanthe $(\mathrm{X})$ & $6 \mathrm{~N}$ & $47 \mathrm{~W}$ & runoff \\
\hline SHALBATANA (S) & $5 \mathrm{~N}$ & $44 \mathrm{~W}$ & modified outflow \\
\hline SIMUD (Si) & $5 \mathrm{~N}$ & $36 \mathrm{~W}$ & $\begin{array}{l}\text { modified outflow } \\
\text { (chaotic terrain) }\end{array}$ \\
\hline TIU (T) & $10 \mathrm{~N}$ & $32 \mathrm{~W}$ & $\begin{array}{l}\text { modified outflow } \\
\text { (chaotic terrain) }\end{array}$ \\
\hline $\operatorname{ARES}(\mathrm{A})$ & $7 \mathrm{~N}$ & $20 \mathrm{~W}$ & outflow \\
\hline Arabia (Ar) & $7 N$ & $329 \mathrm{~W}$ & runoff \\
\hline AUQAKUH (Aq) & $30 \mathrm{~N}$ & $300 \mathrm{~W}$ & fretted \\
\hline HUO HSING (HH) & $30 \mathrm{~N}$ & $293 \mathrm{~W}$ & fretted \\
\hline Elysium (E) & $28 \mathrm{~N}$ & $225 \mathrm{~W}$ & outflow \\
\hline MANGLA (Man) & $7 \mathrm{~S}$ & $151 \mathrm{~W}$ & outflow \\
\hline NIRGAL (N) & $28 \mathrm{~S}$ & $40 \mathrm{~W}$ & runoff (fretted?) \\
\hline $\operatorname{Eos}(E o)$ & $15 \mathrm{~S}$ & $38 \mathrm{~W}$ & outflow \\
\hline LADON (L) & $23 \mathrm{~S}$ & $28 \mathrm{~W}$ & outflow \\
\hline Margaritifer (Mar) & $15 \mathrm{~S}$ & $25 \mathrm{~W}$ & outflow \\
\hline Tritonius (Tr) & $4 \mathrm{~S}$ & $246 \mathrm{~W}$ & fretted \\
\hline Gomer (G) & $3 \mathrm{~S}$ & $234 \mathrm{~W}$ & fretted \\
\hline AL QAHIRA (Al) & $18 \mathrm{~S}$ & $197 \mathrm{~W}$ & runoff (fretted?) \\
\hline MA'ADIM (Maa) & $21 \mathrm{~S}$ & $182 W$ & runoff \\
\hline Hellas (H) & $36 \mathrm{~S}$ & $270 \mathrm{~W}$ & outflow (runoff) \\
\hline Hadriacum $(\mathrm{H})$ & $40 \mathrm{~S}$ & $253 \mathrm{~W}$ & outflow \\
\hline
\end{tabular}

Capital letters denote named channels, and lower case letters, unnamed channels.

*After Sharp and Malin [1975]

channels, divides by the total area, and produces a sizefrequency curve. By referencing this incremental crater frequency diagram to theoretical isochrons previously derived, Hartmann estimates a 'modal or mean age' for his five channels of about $10^{8}$ years. However, this age is suspect if based on small craters because of the possibility of equilibrium with erosional phenomena, and if on large craters because of poor statistics. It seems most likely that it is a minimum age for the ensemble of channels studied by Hartmann.

Another deficiency in Hartmann's analysis is that if the regions illustrated in this paper are indicative of the 'channels' for which he acquired crater counts, at least two of his five features are not easily identified as channels of fluvial origin. Hartmann's Figure 3 shows one of these two, a portion of the floor of the Coprates Chasma portion of the Valles Marineris. This large trough is most likely the result of collapse and wall recession, and the braided texture on the floor is probably the result of wind erosion. Additionally, the floor may be a trap for eolian material, a point illustrated during the 1973 dust storm by the obscuration of floor detail long after the canyon walls were easily observed. In Figure 2 of Hartmann's presentation, most of the area has been modified by the formation and continued degradation of chaotic terrain. While the craters on the floors of these regions may indicate the age of the more areally restricted channels as well as that of the chaotic terrain, this cannot be determined unambiguously. The number of valid channel craters counted by Hartmann thus becomes quite small.

In the present study, craters ranging in size from 0.25 to 16 $\mathrm{km}$ were counted on some 25 major channels on Mars. Not included were the cratered channels of the chaotic and fretted terrains because of the difficulty in delineating between the channels and the smoother portions of the adjacent chaotic and fretted landforms. Table 2 lists photographic data, number and size of craters, and the approximate area of each section of five representative channels. Also listed are similar statistics for some nearby unchanneled surfaces (Tables 3 and 4).

Comparison of the absolute numbers of craters within the channels, using procedures similar to those of Hartmann [1974], yields 'ages' similar to the one that he determined for Mangala. For example, the channel Ladon $\left(23^{\circ} \mathrm{S}, 28.5^{\circ} \mathrm{W}\right.$; see

TABLE 2a. Channels and Intercrater Plains: Individual Crater Counts

\begin{tabular}{|c|c|c|c|c|c|c|c|c|c|c|c|}
\hline \multirow[b]{2}{*}{ Camera } & \multirow[b]{2}{*}{ DAS } & \multirow[b]{2}{*}{ Area, $\mathbf{k m}^{2}$} & \multicolumn{9}{|c|}{ Number of Craters per Increment $(\mathrm{km})$ in Channel } \\
\hline & & & $<0.5$ & $0.5-1$ & $1-2$ & $2-4$ & 4-8 & $8-16$ & $16-32$ & $32-64$ & $64-128$ \\
\hline \multicolumn{12}{|c|}{ Mangala Channel } \\
\hline B & 9628644 & $627(800)$ & $1(1)$ & $1(1)$ & & & & & & & \\
\hline B & 9628924 & $380(1740)$ & $1(1)$ & (i) & & & & & (2) & & \\
\hline B & 12499645 & $1200(300)$ & 2 & $3(2)$ & (1) & & & & & & \\
\hline B & 12499715 & $500(1000)$ & $2(4)$ & $i$ & (2) & & & & & & \\
\hline B & 12499785 & $200(1200)$ & (6) & (1) & I(1) & & & & & & \\
\hline \multicolumn{12}{|c|}{ Ares Channel } \\
\hline A & 7830583 & $3.6 \times 10^{4}\left(15.9 \times 10^{4}\right)$ & & & & (8) & $2(8)$ & $2(10)$ & (4) & (4) & (1) \\
\hline B & 7758803 & $825(j 450)$ & 2 & $3(3)$ & I(1) & (1) & (1) & & & & \\
\hline B & 9233289 & $1145(500)$ & 2 & $3(2)$ & 2 & & & & (1) & & \\
\hline B & 12362181 & $1000(2100)$ & $1(6)$ & $1(3)$ & (2) & (2) & (2) & (1) & & & \\
\hline \multirow{2}{*}{\multicolumn{12}{|c|}{ Ma'adim Channel }} \\
\hline & & & & & & & & & & & \\
\hline A & 6606703 & $\begin{array}{c}8500 \\
\left(2.3 \times 10^{5}\right)\end{array}$ & & & & $2(59)$ & $2(43)$ & (39) & (25) & (9) & (1) \\
\hline \multicolumn{12}{|c|}{ Elysium Channels } \\
\hline B & 8910724 & $700(3500)$ & $5(10)$ & $2(4)$ & $1(4)$ & (1) & & & & & \\
\hline B & 10313804 & 1100 & $7(11)$ & $5(9)$ & $6(6)$ & & & & & & \\
\hline B & 10313874 & $(5500)$ & & & & & & & & & \\
\hline \multicolumn{12}{|c|}{ Ladon Channels } \\
\hline A & 6426803 & $5700\left(1.15 \times 10^{5}\right)$ & & & & $1(20)$ & $2(12)$ & (7) & (2) & (2) & (2) \\
\hline B & 9376438 & 3000 & 2 & $4(3)$ & 1 & (1) & 2 & & & & \\
\hline B & 9376504 & $(3000)$ & & & & & & & & & \\
\hline
\end{tabular}

Craters on adjacent plains are indicated in parentheses. 
Figure 3) has two craters between 4 and $8 \mathrm{~km}$ in diameter within an area of approximately $6000 \mathrm{~km}^{2}$, which implies an age from 1.0 to $8 \times 10^{9}$ years, comparable to Hartmann's values of $6 \times 10^{8}$ to $5 \times 10^{9}$ years for Mangala. Similar calculations for the other channels in Table 1 yield similar results. Most of the channels appear to have cratering ages which may be af the order of billions of years. It must be noted that an absolute crater age for the channels is dependent on the impact rate assumed and cannot be uniquely determined by these methods.

Figure 4 illustrates two ways in which crater count data can be presented. Figure $4 a$ compares the incremental crater frequency populations summed for all the channels studied by Hartmann with those presented in this work. The isochrons were derived by Hartmann for a Mars to moon flux enhancement of $8: 1$. There are two important things to note in this figure: (1) the general similarity in the two data sets (open versus closed dots) and (2) the relative antiquity of this average age for martian channels ( $\sim 10^{\ominus}$ years), even assuming this moderately heavy bombardment of Mars. The low data point at $3 \mathrm{~km}$ is associated with the falloff of A camera resolution; the data for craters smaller than $2 \mathrm{~km}$ represent crater counts on the higher-resolution B frames. Hartmann's data show a similar but less pronounced effect, possibly owing to the difference in bin assignment. Figure $4 b$ compares cumulative crater populations on a variety of regional terrains. The two distinet groupings reflect A and B camera data sets. Soderblom et al. [1974] suggest that the population of craters smaller than about $1.5-$ to $2-\mathrm{km}$ diameter is in erosional equilibrium and that the number of small craters will therefore be largely independent of the age of the surface, reflecting instead more recent processes. In particular, they suggest that only slight variations in crater density will be seen for the small craters and that no temporal information can be derived from these craters. The upper set of data in Figure $4 b$ support this interpretation. However, the lower set of data reflect counts of craters large enough to survive the erosional processes and thus are indicative of the relative ages of the surfaces. It is clear from Figure $4 b$ that the large martian channels are older on the average than the most heavily cratered (and thus oldest) Tharsis plains, about the same age as the Lunae Planum plains, and younger than the intercrater plains of the heavily cratered terrain. This determination of relative age is independent of specific flux rate.

\section{Noncrateriform Features Superimposed on Channels}

It is important to ask if any other landforms or deposits are superposed on channels. At least two types of materials can be seen in places to lie over the channel topography in Mariner 9 photography. One is the major plains units of the northern hemisphere, and the second is the subpolar debris mantles described by Soderblom et al. [1973].

A major distinction in surface morphology on Mars exists between cratered 'uplands' in the southern half of the planet and relatively uncratered 'lowlands' in the northern half. Several papers have set limits on the position of these lowland plains deposits within the overall stratigraphic history of Mars [Soderblom et al., 1974; Jones, 1974; Carr et al., 1973; McCauley et al., 1972]. Thus if one could place the channels in relation to the plains units, the channels could be related to the general scheme of martian chronology. The location of many channels near boundaries between major physiographic provinces would seem to make this a feasible task. Unfortunately,

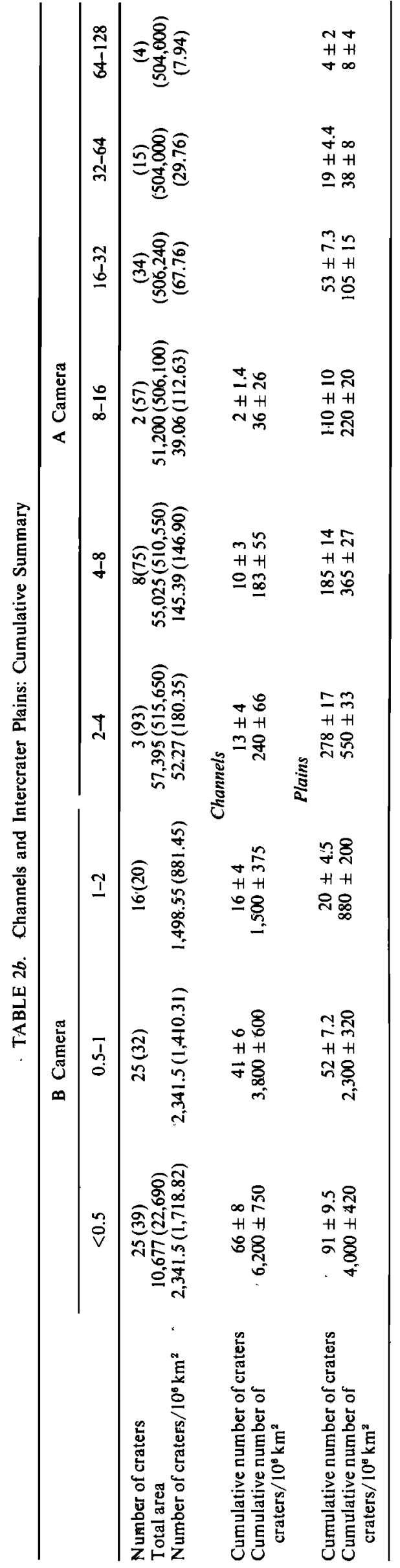


TABLE 3. Lunae Planum Plateau Plains $\left(0^{\circ}, 68^{\circ} \mathrm{W}\right)$

\begin{tabular}{|c|c|c|c|c|c|c|c|c|c|}
\hline \multirow[b]{2}{*}{ DAS } & \multirow[b]{2}{*}{ Area, $\mathbf{k m}^{2}$} & \multicolumn{8}{|c|}{ Number of Craters per Increment in Kilometers } \\
\hline & & $<0.5$ & $0.5-1$ & $1-2$ & $2-4$ & 4-8 & $8-16$ & $16-32$ & $32-64$ \\
\hline $\begin{array}{l}7399213 \\
7399353 \\
7399703 \\
7471243\end{array}$ & $\begin{array}{l}2,268 \\
2,408 \\
4,292 \\
2,365\end{array}$ & $\begin{array}{l}2 \\
3 \\
1\end{array}$ & $\begin{array}{r}3 \\
11 \\
7 \\
7\end{array}$ & $\begin{array}{l}5 \\
9 \\
5 \\
4\end{array}$ & $\begin{array}{l}2 \\
1 \\
2\end{array}$ & $\begin{array}{l}1 \\
1\end{array}$ & 1 & & \\
\hline $\begin{array}{l}7471068 \\
7471138 \\
7471278\end{array}$ & $\begin{array}{l}206,255 \\
207,966 \\
225,540\end{array}$ & & & & $\begin{array}{l}46 \\
66 \\
35\end{array}$ & $\begin{array}{r}7 \\
9 \\
16\end{array}$ & $\begin{array}{l}2 \\
5 \\
5\end{array}$ & $\begin{array}{l}6 \\
4 \\
4\end{array}$ & 1 \\
\hline $\begin{array}{l}\text { Totals } \\
\text { Cumulative number } \\
\text { of craters } \\
\text { Cumulative number } \\
\text { of craters } / 10^{6} \mathrm{~km}^{2}\end{array}$ & $\begin{array}{r}11,333 \\
639,761\end{array}$ & $\begin{array}{c}6 \\
65 \pm 8 \\
5700 \pm 700\end{array}$ & $\begin{array}{c}28 \\
59 \pm 7.7 \\
5200 \pm 700\end{array}$ & $\begin{array}{c}23 \\
31 \pm 5.5 \\
2750 \pm 480\end{array}$ & $\begin{aligned} 5 \\
147 \\
8 \pm 3 \\
206 \pm 14 \\
700 \pm 250 \\
320 \pm 20\end{aligned}$ & $\begin{array}{c}2 \\
32 \\
3 \pm 1.7 \\
59 \pm 7.7 \\
265 \pm 150 \\
92 \pm 12\end{array}$ & $\begin{array}{rl}1 & 12 \\
1 & \pm 1 \\
27 & \pm 5.2 \\
88 & \pm 88 \\
42 & \pm 8\end{array}$ & $\begin{array}{c}14 \\
15 \pm 4 \\
23 \pm 6\end{array}$ & $\begin{array}{c}1 \\
1 \pm 1 \\
1.6 \pm 1.6\end{array}$ \\
\hline
\end{tabular}

such is not the case, because most Mariner 9 photography is of insufficient resolution. Even when a photograph might show clear-cut relationships between plains units and channels, debris mantles obscure the contact. The following two examples illustrate these limitations and are indicative of the type of data available for analysis.

Figure 5 shows an unnamed channel located at the boundary between heavily cratered terrain and a less cratered plains near $0-5^{\circ} \mathrm{N}, 60.8^{\circ} \mathrm{W}$. The plains unit comprises the eastern part of the Lunae Planum plateau, which has been determined by independent analyses to be the oldest postuplands terrain [Soderblom et al., 1974; Jones, 1974; Chapman. 1974; Arvidson, 1974]. The channel ( $450 \mathrm{~km}$ long, $12 \mathrm{~km}$ wide) debouches northward down a regional slope from an area of chaotic terrain $\left(10^{4} \mathrm{~km}^{2}\right)$ and is classified as an outflow channel on the basis of its head form and tapered and shallow distal termination. Some $50 \mathrm{~km}$ below the head of the channel it divides into two north-trending, roughly parallel distributaries. The eastern branch, approximately $400 \mathrm{~km}$ long, follows along the terrain boundary and appears to tap other small chaotic regions. The western branch lies some $40 \mathrm{~km}$ to the west, within the plains unit.

The morphology of these channels changes as they cross the terrain boundary. The western branch fades in apparent topographic relief north and west of the fork, and the western wall of the east branch appears subdued or missing. A subdued craterlike form connected to the western branch immediately west of the divide suggests comparable burial. About $100 \mathrm{~km}$ north of the divide, both the eastern and western branches reacquire more definite topographic relief, although they remain subdued. Eventually, both channels dwindle and die within the plains unit. These characteristics suggest that the material of the plains overlies many portions of the channels, the occasional spatial resurgence of topographic form being the result of incomplete burial by the thin volcanic units which are evidenced by marelike ridges within the local area.

A second example is the mouth of Mangala as shown at high resolution (Figure 6). Mangala is distinctive in that it is one of the few channels that terminate at an abrupt cliff. Although not visible in Figure 6, flow fronts seen on the nearby plains surface suggest that the plains are of volcanic origin. The concordance of the channel bed and the plain suggests that either a large portion of the plain near the channel mouth is alluvial or the presumably volcanic plains have flooded over portions of the channel and its deposits. The slight albedo feature near the mouth of the channel may be evidence of alluviation but cannot be distinguished from other light albedo markings of probable eolian origin. Evidence for eolian-related albedo features is seen in the two small craters with dark streaks on the plain beneath the channel. It appears possible, however, that the darker plains material north of the channel mouth has embayed the lighter material. It is concluded that the plains are primarily of volcanic origin and have flooded and buried the Mangala channel deposits.

Further study of Mangala reveals a possible extension of the channel for $460 \mathrm{~km}$ south of the presumed source area (Figure 7). If this is indeed part of the Mangala system, then the highly cratered plain transecting the mid-portion of the original chan-

TABLE 4. Oldest Tharsis Volcanic Plain $\left(30^{\circ} \mathrm{N}, 122^{\circ} \mathrm{W}\right)$

\begin{tabular}{|c|c|c|c|c|c|c|c|c|c|}
\hline \multirow[b]{2}{*}{ DAS } & \multirow[b]{2}{*}{ Area, $\mathrm{km}^{2}$} & \multicolumn{8}{|c|}{ Number of Craters per Increment in Kilometers } \\
\hline & & $<0.5$ & $0.5-1$ & $1-2$ & $2-4$ & $4-8$ & $8-16$ & $16-32$ & $32-64$ \\
\hline 8370889 & 4,408 & 23 & 8 & 3 & 1 & & & & \\
\hline 6967418 & 235,277 & & & 6 & 10 & 4 & 2 & & \\
\hline 6967768 & 357,780 & & & 8 & 6 & 5 & 6 & 5 & \\
\hline 7039728 & 357,576 & & & & 17 & 5 & 2 & 2 & \\
\hline 8370854 & 401,921 & & & & 5 & 11 & 7 & 2 & \\
\hline Totals & 4,408 & 23 & 8 & 3 & 1 & & & & \\
\hline & $1,349,554$ & & & 14 & 38 & 25 & 17 & 9 & \\
\hline $\begin{array}{l}\text { Cumulative number } \\
\text { of craters }\end{array}$ & & $35 \pm 6$ & $12 \pm 3$ & $\begin{aligned} 4 & \pm 2 \\
103 & \pm 10\end{aligned}$ & $\begin{array}{r}1 \pm 1 \\
89 \pm 9\end{array}$ & $51 \pm 7$ & $26 \pm 5$ & $9 \pm 3$ & \\
\hline $\begin{array}{l}\text { Cumulative number } \\
\text { of craters } / 10^{\mathrm{A}} \mathrm{km}^{2}\end{array}$ & & $7900 \pm 1400$ & $2700 \pm 700$ & $\begin{array}{c}900 \pm 450 \\
76 \pm 7\end{array}$ & $\begin{array}{c}227 \pm 227 \\
66 \pm 7\end{array}$ & $38 \pm 5$ & $19 \pm 4$ & $6.7 \pm 2.2$ & \\
\hline
\end{tabular}




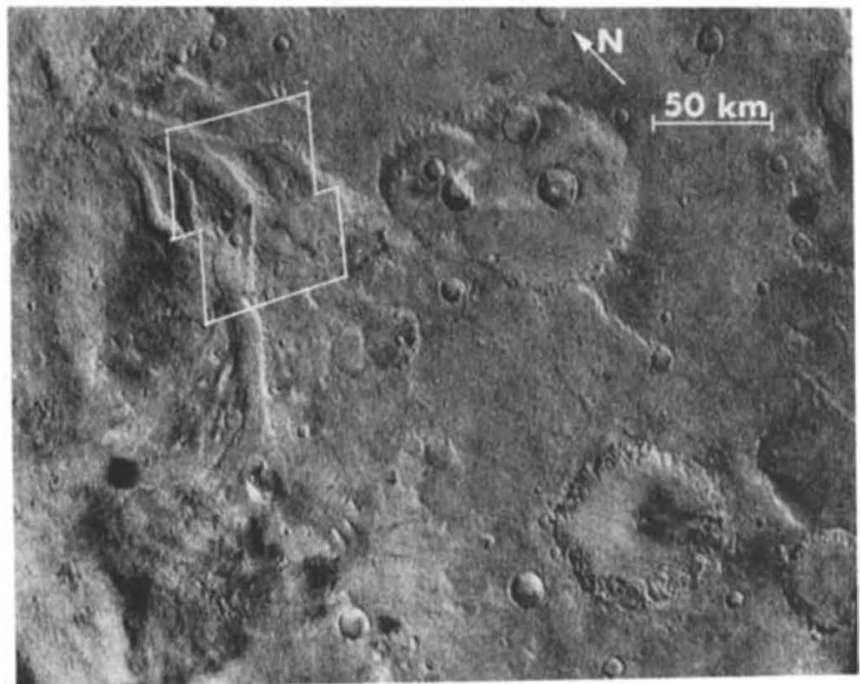

Fig. $3 a$

Fig. 3. Ladon Valles $\left(28^{\circ} \mathrm{W}, 23^{\circ} \mathrm{S}\right)$. (a) A frame of Ladon Valles, showing location of B frame mosaic (see part $b$ ). Channels debouch into large basin to the north (DAS 6426808). (b) B frame mosaic of Ladon Valles. Numerous craters are seen on the channel formations, the largest about $8 \mathrm{~km}$ in diameter. The images have poor definition owing to high sun conditions (sun elevation angle, $70^{\circ}$; phase angle, $50^{\circ}$ ). Rotation of top frame is the result of spacecraft and scan platform motion (DAS 9376439, 9376509).

nel is younger than the channel, making Mangala extremely old.

Debris mantles may have played a role in the evolution of the martian surface forms. Soderblom et al. [1973] have postulated the presence of subpolar blankets which modify small crater abundances, crater morphology, and central peaks at latitudes greater than $30^{\circ}-40^{\circ}$ in both hemispheres. They estimate the thickness at from 0.1 to $1 \mathrm{~km}$ and speculate that the materials are derived from the polar sedimentary deposits. Subsequently, Soderblom et al. [1974] suggest that the equatorward boundary of this mantle moves north and south in phase with the periodic obliquity variations described by Ward [1973, 1974]. They recognized four zones: deeply mantled poleward of $+40^{\circ}$, thinly mantled from around $+40^{\circ}$ to $-15^{\circ}$ largely unmantled from $-15^{\circ}$ to $-40^{\circ}$, and deeply mantled poleward of $-40^{\circ}$. These mantles are useful in setting age limits on the youngest channel features.

Debris mantles may be responsible for the paucity of large channels south of $-40^{\circ}$. Two channels within a few degrees of the mean boundary of the mantle (and also near a probable source of dust, the Hellas Basin) are shallow and subdued (Figure 8). Narrow angle frames show craters with features characteristic of mantling (Figure 9). It seems likely that channels further south would not be visible through even thicker mantle deposits.

Nearly all channels studied show local effects of mantling, usually in slight but distinct changes in the morphology of the small, superposed craters. In some instances the effects are strong, and in others they are less evident; all are correlated with crater morphology variations characteristic of large-scale regional mantling. No evidence is found of preferential deposition or erosion on channel floors.

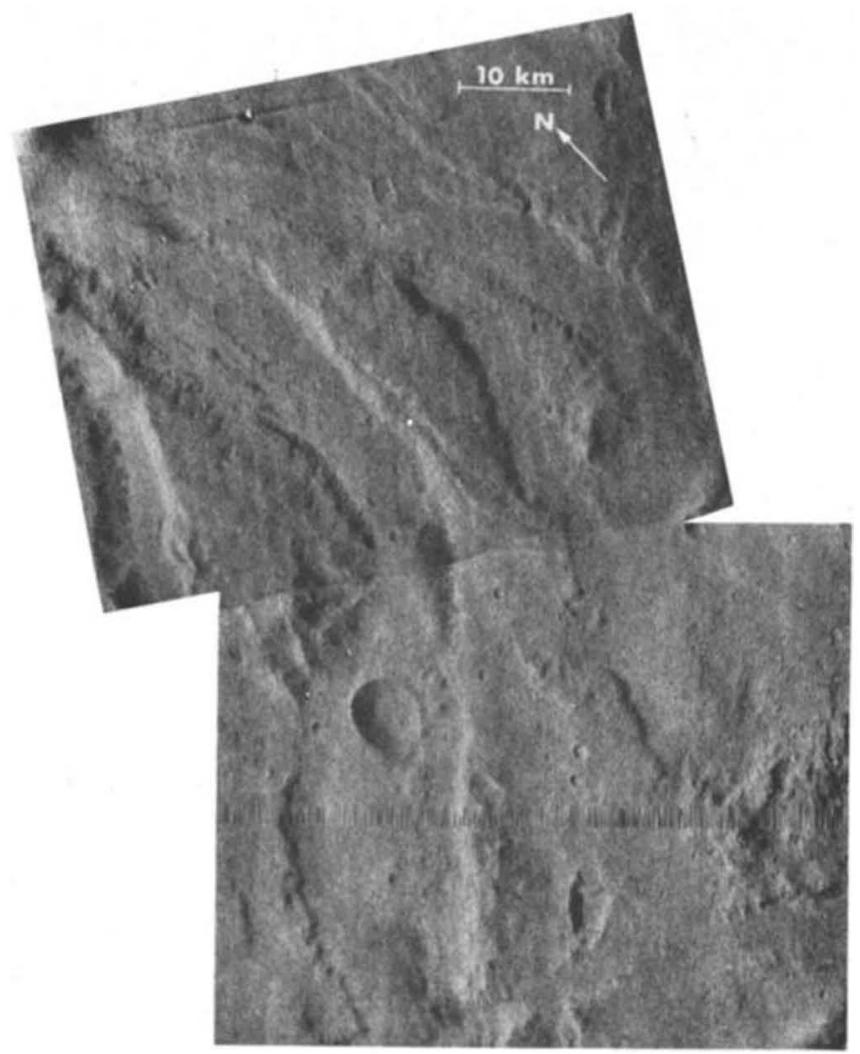

Fig. $3 b$

The Elysium channels (Figures 10 and 11) are anomalous in both location and form. Narrow angle high-resolution images show an extremely subdued apparent cross section. Crater morphologies and light and dark patches typically hundreds of square kilometers in scale suggest the presence of a discontinuous mantle over the entire Elysium region. One possible explanation for the appearance of these channels is that they are formed in a material more resistant than that into which other large channels are cut. In this case the channels are younger than the plains. On the other hand, erosional landforms and mantle relationships are consistent with a moderately thin uniform blanket of a terrain-conforming semicoherent material currently under erosional attack by eolian processes. In this case the channels are older than the present plains surface. It is likely that the Elysium channels owe their existence to the presence of the nearby Elysium volcanic field, either as a source of juvenile volatiles associated with magmatic activity or as the source of a tuff or ash deposit to mantle the surrounding terrain. The number of craters superimposed on the Elysium channels suggest a moderate age, but the other relationships discussed above indicate that these channels are probably the youngest studied in this work.

The findings of this section may be summarized as follows.

1. A significant number of craters are superposed on channels.

2. Although the numbers of craters are less than on the surrounding surfaces, they are comparable to the population of craters on older martian plains.

3. A few channels, in no other way differing from other channels, appear to be covered by older plains material.

4. Debris mantles locally cover many channels. 

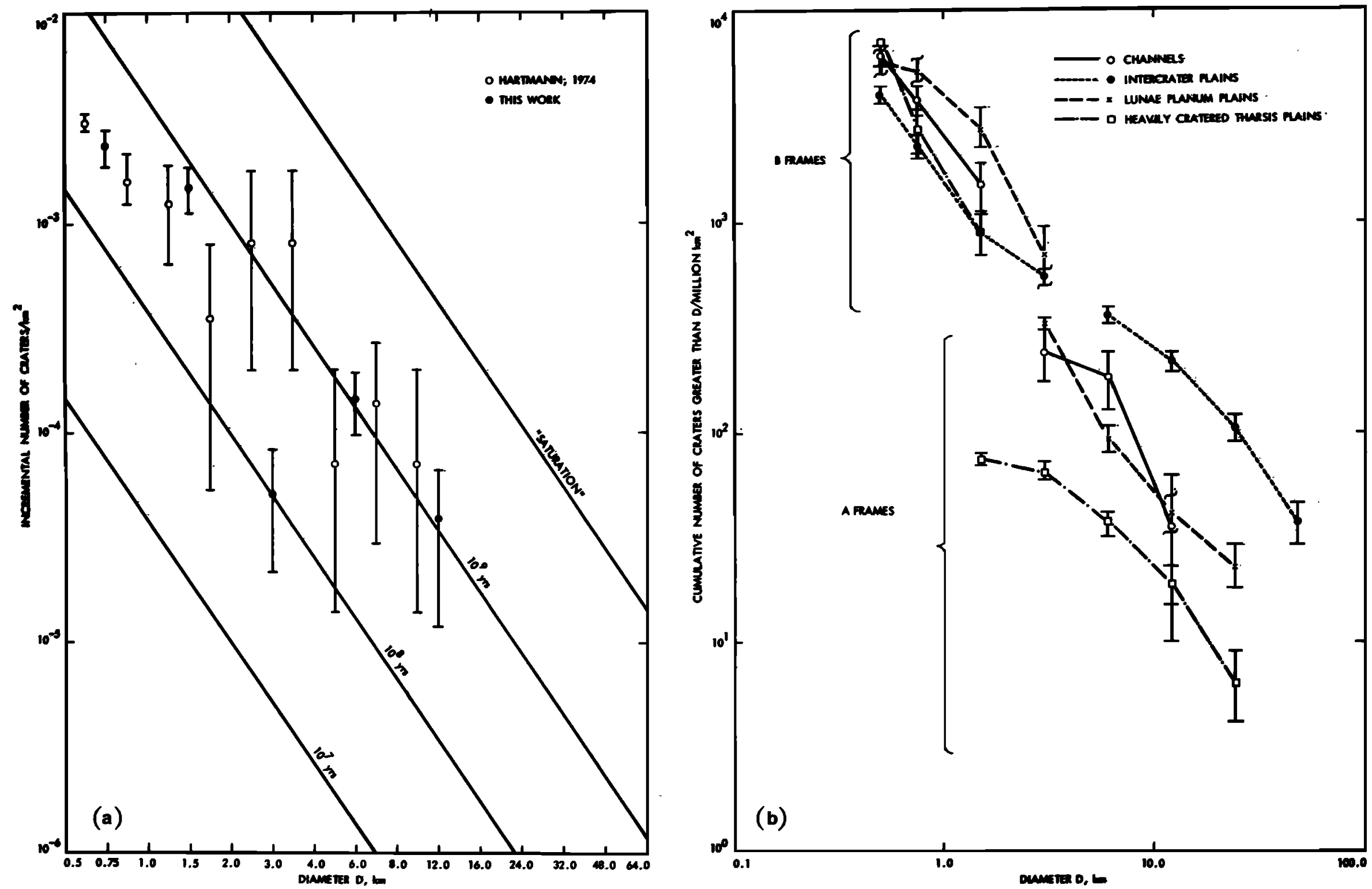

Fig. 4. Crater counts on martian channels. (a) Incremental crater counts, after Hartmann [1974]. Error bars are rms standard deviations. (b) Cumulative crater counts, comparing crater populations on the channels with the populations on the surfaces immediately adjacent to the channels (intercrater plains), on the Lunae Planum plateau plains, and on the most heavily cratered portion of the Tharsis volcanic plain. Note that the counts on B frames cluster together, as noted by Soderblom et al. [1974], who suggest that the small crater population is controlled by eolian debris blankets. Note, too that the relative position of the craters seen on $A$ frames suggests an age for the channels comparable to that of the older plains unit 

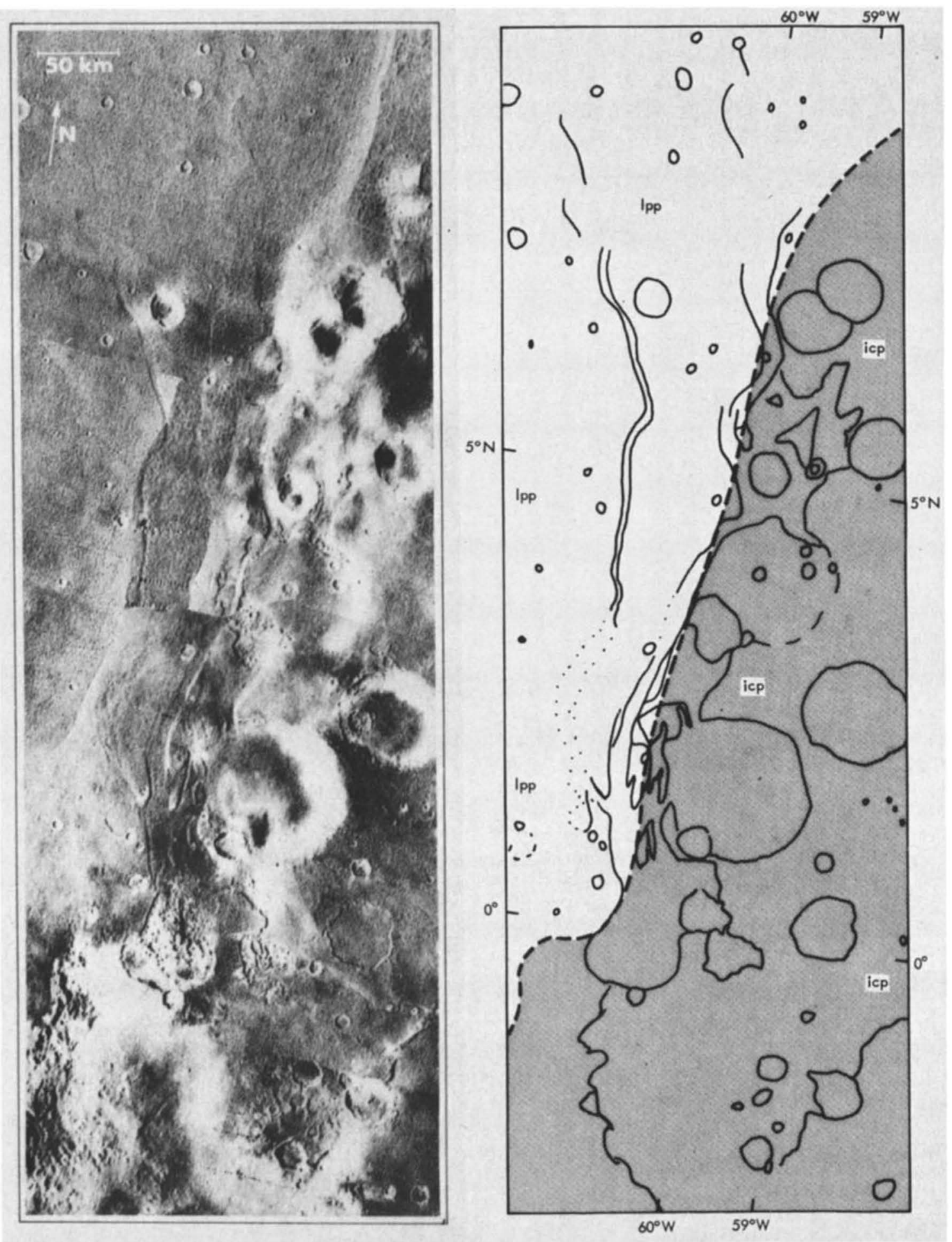

Fig. 5. Unnamed channel near Lunae Planum $\left(60^{\circ} \mathrm{W}, 2^{\circ} \mathrm{N}\right)$. Left: Mariner 9 A frame mosaic showing channels which traverse the boundary between heavily cratered uplands and moderately cratered plains (the Lunae Planum plateau). These outflow channels appear subdued, and in places sections are missing within the plains. It is suggested that the channels are overlain by volcanic material (DAS 747I138, 7471208, 7471558, 7542958, 7543028). Right: Sketch map of unnamed channel, showing location of channel with respect to terrain boundaries.

\section{Channels Superimposed on Other Features}

The oldest terrain on Mars is characterized by large craters, basins and basin-related structures, and intercrater plains and is dominant in the southern hemisphere [McCauley et al., 1972; Carr et al., 1973; Soderblom et al., 1974]. In this section the relationships between channels and the older features will be examined.

As noted previously [McCauley et al., 1972; Milton, 1973; Sharp and Malin, 1975], a large number of channels extend out from regions of chaotic terrain. Although the largest of these 


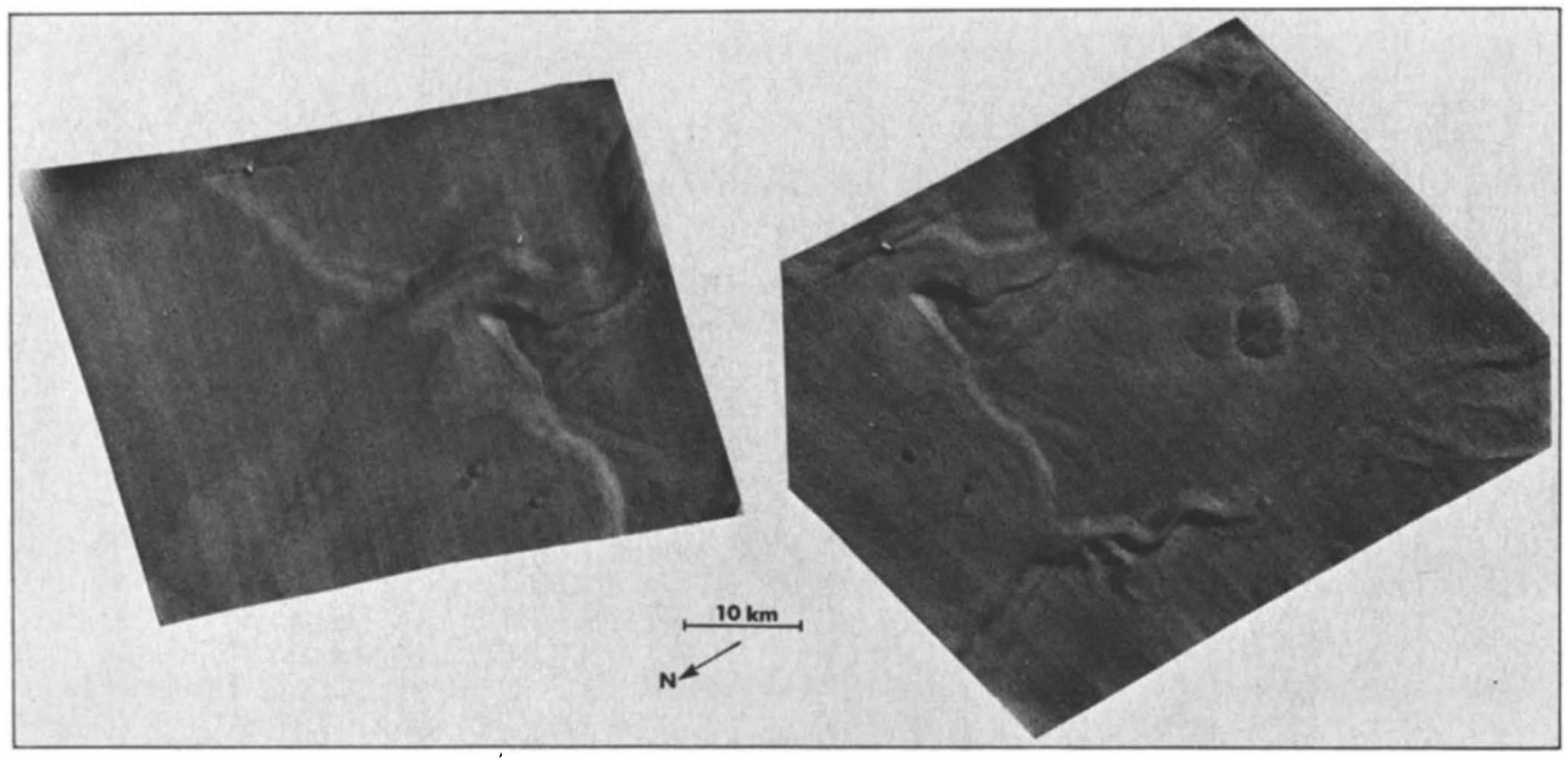

Fig. 6. Mangala Vallis: mouth area. Stereo pair of Mariner 9 high-resolution frames, orthographically projected, showing the mouth of Mangala channel. The lack of contrast is the result of poor illumination conditions: $67^{\circ}$ sun elevation angle, $20^{\circ}$ phase angle. The dark material north of the escarpment appears to embay the lighter material near the mouth, suggesting that the alluvial features which might be expected to accompany a large channel are buried by the plains material. Note at the extreme right the incision of the crater floor (DAS 10686114 (left); 9556549 (right)).

chaotic areas are irregularly shaped, many are roughly circular and clearly occupy craters (Figures 12 and 13). Separate areas of chaos are often connected by broad flat-floored channels, which usually circumvent but occasionally cut through the walls of craters that pock the surface between them. In tangentially grazing encounters the channels appear to erode crater rims by undermining and collapse. However, the eastern part of Ares channel encounters two craters nearly head-on and appears to have breached their rims (Figure 13). Mangala, an outflow channel not associated with chaotic terrain, also appears to have breached two relatively subdued $30-\mathrm{km}$ craters, one over $180 \mathrm{~km}$ downstream from the head of the channel (Figures 1 and 7).

Ma'adim, a large runoff channel in a densely cratered region (Figure 1), appears to have attacked craters through both grazing and head-on erosion. Two $30-\mathrm{km}$ craters are breached some $150 \mathrm{~km}$ above the mouth of the channel, and about a quarter of the rim of another $30-\mathrm{km}$ crater has been trimmed away by the channel. Nirgal, another runoff channel in a somewhat less densely cratered area, breaches a $20-\mathrm{km}$ crater at its mouth.

The best examples of fretted channels are in a region of fretted terrain (areas of isolated buttes and mesas formed by the apparent deterioration of 'highland' terrain) near $38^{\circ} \mathrm{N}$, $340^{\circ} \mathrm{W}$ (Figure 1). Here it appears that numerous craters have been joined by the fretting process, integrated with the channels by both tangential cutting and perpendicular breaching.

Although Mars has many large basins, only one, Hellas, has visibly associated channels. Two large channès, both immediately east of the basin, are consequent upon the basin topography (Figure 8). Both are aligned along the topographic gradient and have formed around and through the mountainous features associated with the basin structure.

While craters and basins are among the oldest landforms, $75 \%$ of the most heavily cratered area consists of relatively smooth rolling plains which occupy the area between craters. Called by various authors 'plateau plains' or 'heavily cratered plains,' these intercrater areas will be here called 'intercrater plains.' The possible origin and makeup of these plains is currently under study [Wilhelms, 1974; Malin, 1976]. Although the morphologies of channels developed within these plains bear strongly on both their origin and the nature of the underlying materials, this discussion will be limited to age relationships (for a more detailed treatment, see Malin [1976]).

Most channels within the heavily cratered regions of Mars are necessarily developed within the intercrater plains, since these plains cover the most area. Additionally, no large channels are seen in areas where the surface is essentially saturated with large craters.

The findings of this section may be summarized as follows.

1. Almost all of the oldest features on Mars-large craters, basins, and intercrater plains-predate the major channels visible on the surface.

2. By implication, the processes of chaos formation and fretting were operative at the time of channeling.

\section{Discussion}

How old are the martian channels, and what is their place in martian history? The reader is forewarned that this section presents interpretations of increasingly speculative nature.

The first objective of any dating process is to place features in relative order. Since most major channels are found within relatively old heavily cratered regions, one concludes that they are either older than the plains which cover the remainder of the planet, having been buried or destroyed in the plains making process, or that channels originate through processes operative only in cratered regions. Such a process would have to be lithospheric (since atmospheric processes rarely follow geologic boundaries), but this seems unlikely, since young volcanic plains devoid of channels (except in Elysium) must be 
underlain by older crust in which the process would presumably be active. Since the Elysium channels most likely represent phenomena unique to the Elysium region, they are not really representative of large martian channels. Thus the interpretation that channels are older than many of the plains units is favored. This conclusion is supported by the observation of plains and crater relationships to channels already described. Subsequent to the creation of large craters, basins, and the intercrater plains came the formation of portions of the chaotic and fretted terrains and associated channels. Some of the channels predate the formation of the oldest volcanic plains; others were formed shortly after these plains. The large channels are therefore among the older features of the surface of Mars.

Minimum age of channels is less clearly defined. Superposed craters and the mantled appearance of channels and indenting craters indicate that most channels cannot be young in an absolute sense. The Elysium channels are possibly as young as the Elysium plains, which are still quite old in relation to other martian plains units. Aside from small, fretted channels discussed by Sharp and Malin [1975] the only evidence suggesting that some channels are young involves a single $2.5-\mathrm{km}$ crater (Figure 14), which indents one part of a strand of Mangala channel and appears to be truncated by another strand [Hart-
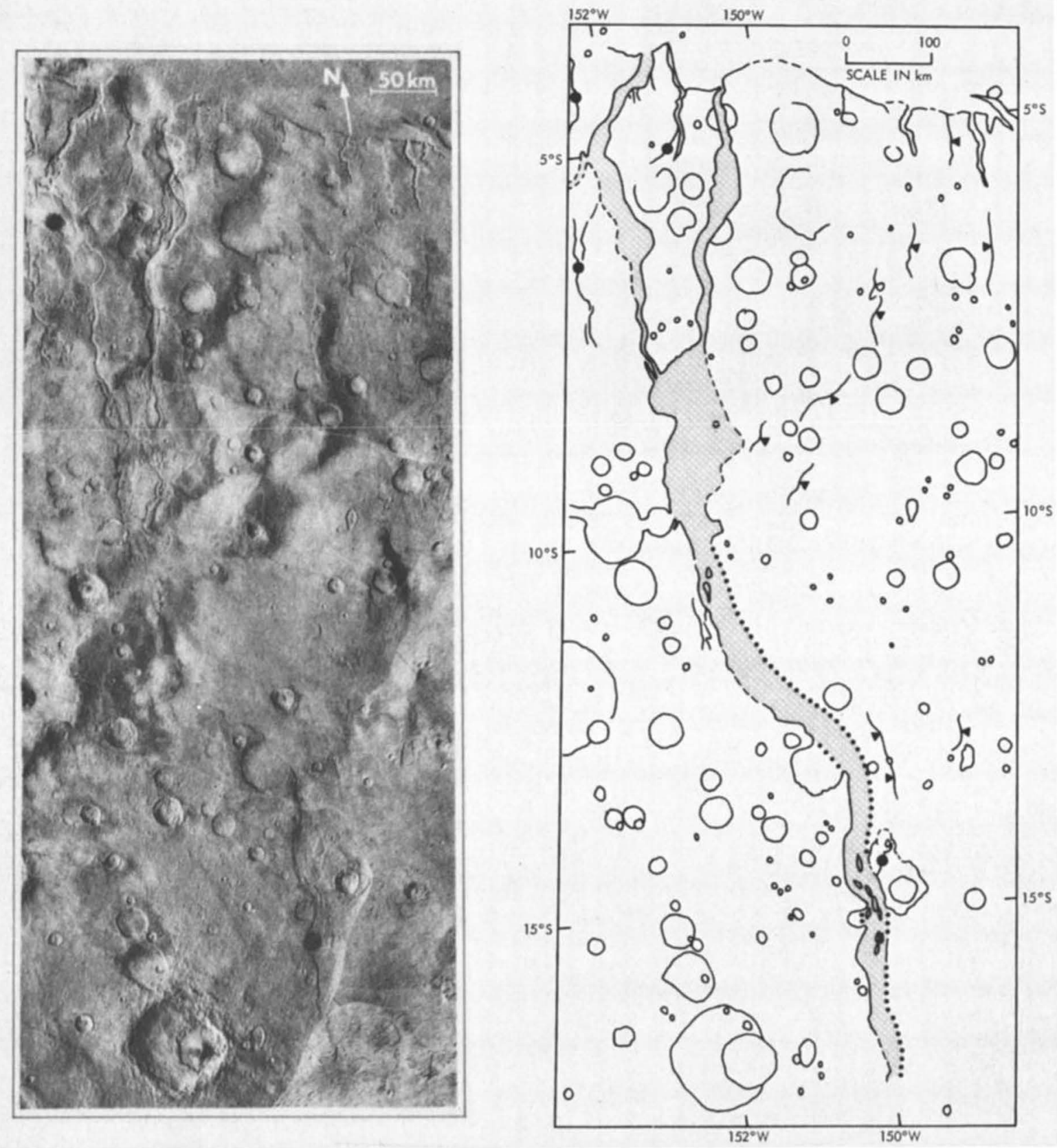

Fig. 7. Mangala Vallis $\left(151^{\circ} \mathrm{W}, 5^{\circ} \mathrm{S}\right)$. Left: Mariner $9 \mathrm{~A}$ frame mosaic showing possible extension of channel some 400 $\mathrm{km}$ beyond the hummocky region near middle left. The extension is characterized by an east-facing escarpment with small conformal islandlike ridges along the southern reach. The west-facing portion of the channel is no longer visible, suggesting removal, perhaps by burial by volcanic plains. The large numbers of craters superposed on the plains immediately east of the visible channel indicate significant antiquity, and the channel would necessarily be older if it is covered by these plains (DAS 6822658, 6822728, 6822798, 8297424, 8297494). Right: Sketch map of Mangala Vallis; shaded area indicates channel extension. 

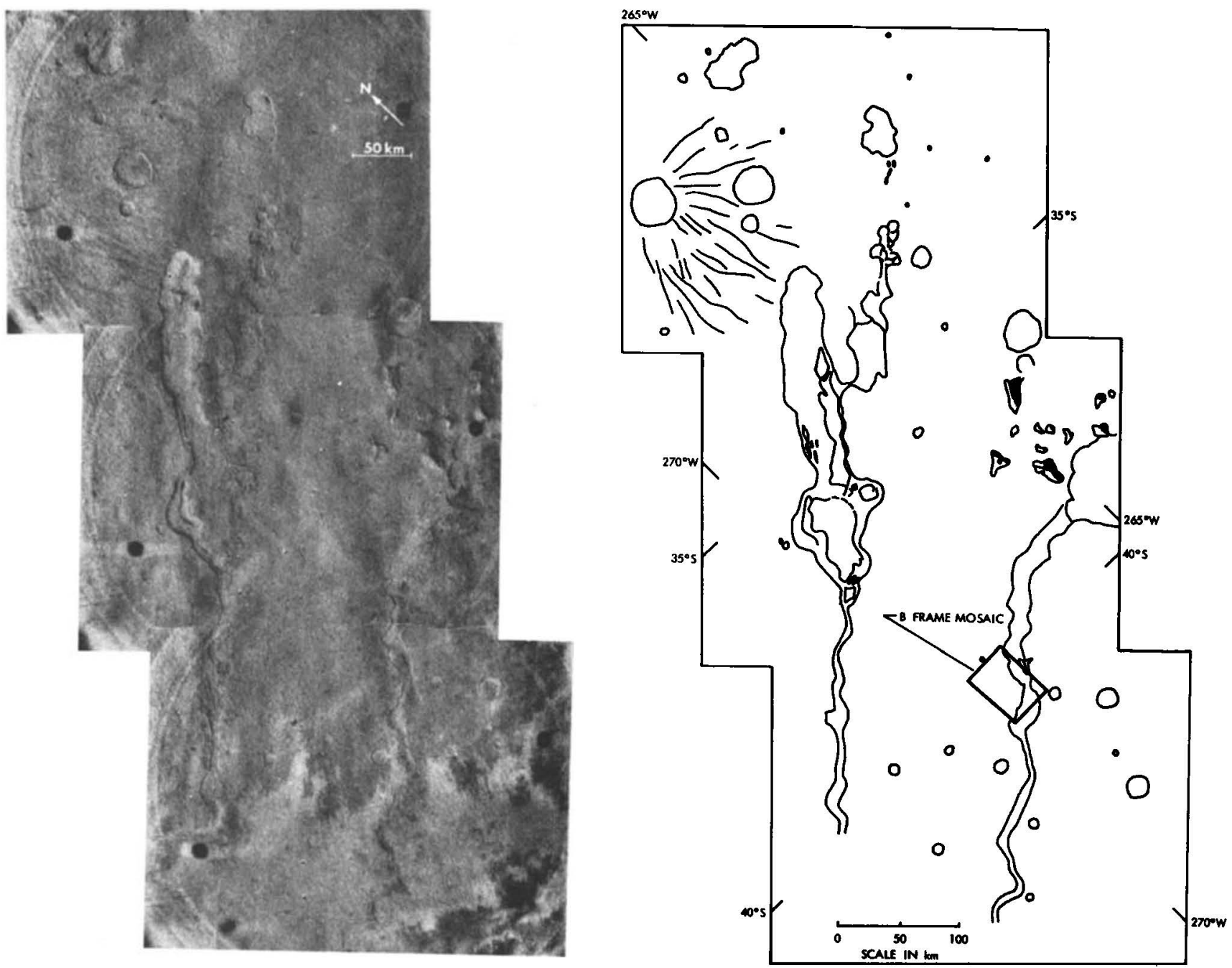

Fig. 8. Unnamed channels near the Hellas Basin $\left(270^{\circ} \mathrm{W}, 36^{\circ} \mathrm{S}\right)$. (a) Photomosaic of Mariner 9 A frames showing extremely subdued topography of two channels near a region of thick debris mantling. Channel on left is abruptly terminated in a large depression on the flanks of a possible volcanic construct. The right channel continues headward some $1000 \mathrm{~km}$. Low-contrast photographs are the result of poor illumination conditions (sun elevation angle, $48^{\circ}$; phase angle, $45^{\circ}$ ) (DAS 6031098, 6031168,6031238). (b) Sketch map of Hellas channels, showing location of channels and position of B frame mosaic (Figure 9).

mann, 1974]. Hartmann argues in favor of this sequence of events because of (1) the apparent noncircularity of the crater on its eastern rim and (2) the appearance of bright rays of the crater superposed on the older but not the younger channel strand. Since appearances in Mariner 9 photographs can be deceiving, a number of computer-enhanced versions of the frame in question have been prepared. From these frames the following conclusions are reached. The noncircularity of the crater is only apparent. When corrections for viewing geometry and removal of artifacts associated with the filtering algorithm used in the computer processing are made, no deviation from circularity is detectable. In addition, when one considers that many craters display some polygonality, any argument based on departures from perfect circularity must be suspect. The special image processing further suggests that the ray system is most likely photometric shading associated with slight changes of slope, accentuated by the enhancing process practiced on all Mariner photos. This is supported by the rarity of rays associated with martian craters, probably because of subsequent erosional or depositional activity. Craters with rays are never seen without continuous ejecta blankets, and the absence of such blankets around this crater suggests that it is not rayed. These considerations throw doubt on Hartmann's [1974] assignment of a relatively youthful age to some of the activity in Mangala channel.

Finally, it is theoretically possible to assign absolute ages to the channels by using cratering curves proposed by Hartmann and Soderblom. When Hartmann's [1973, 1974] curves are used, the channels do not appear to be substantially younger than $10^{8}$ years. When a flux comparable to that of the moon is used [Soderblom et al., 1974], ages in excess to the age of the solar system are obtained, suggesting that the channels date from the period when the bombardment of Mars was in excess to that of a linearly extrapolated flux. This period, called the 'end of heavy bombardment' or 'terminal bombardment,' occurred on the moon around 4 billion years ago. Soderblom et al. [1974] propose a similar history and time scale for Mars, which could make the channels about 4 billion years old.

In conclusion, the channels on Mars appear to be old, in some places older than the oldest volcanic plains unit. No 


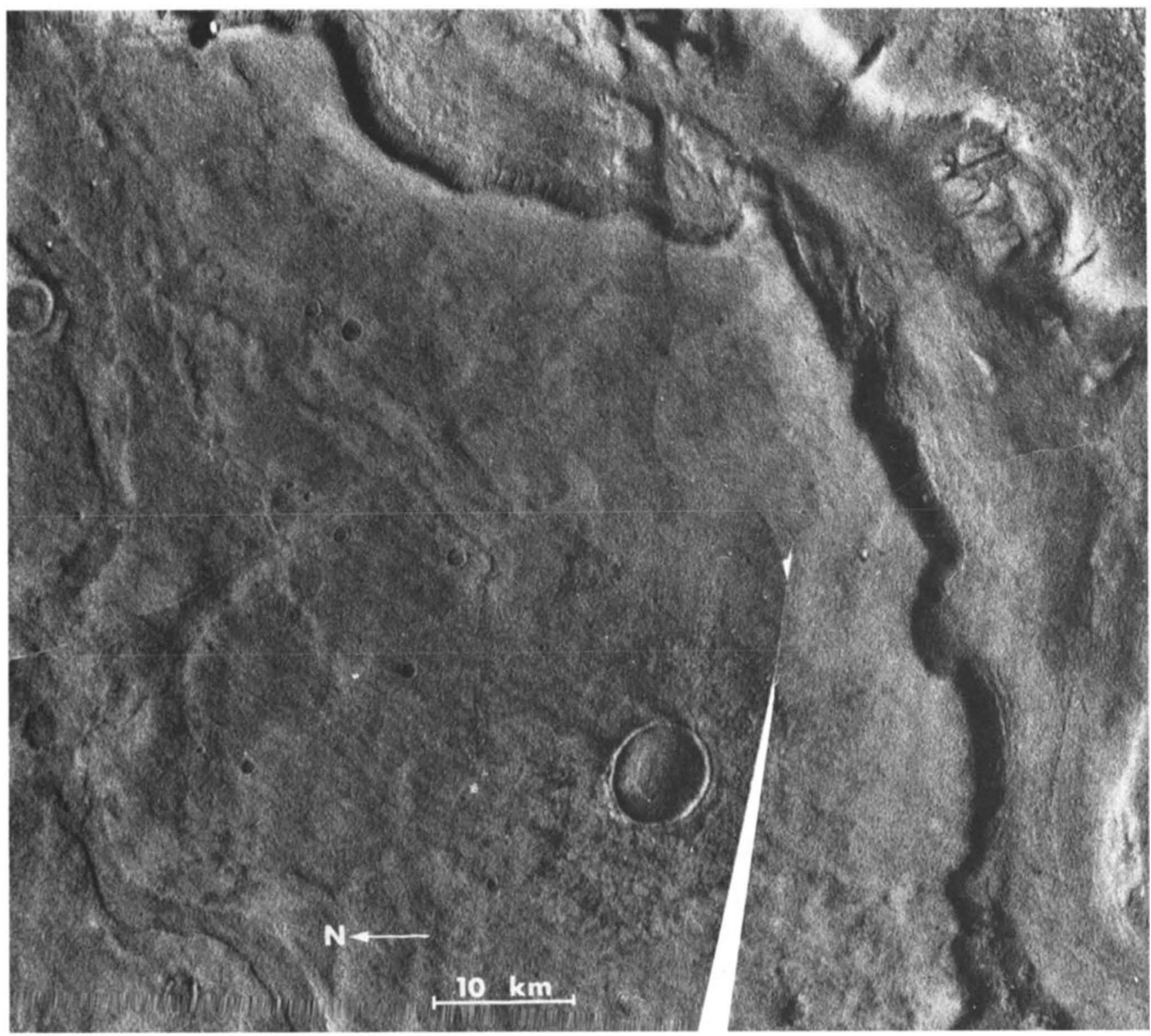

Fig. 9. Unnamed channel near Hellas Basin. Hıgh-resolutıon photomosaic of Mariner 9 B frames, showing subdued nature of channels near Hellas. Landforms show features diagnostic of mantling: gently rolling smooth surfaces, subdued crater rims, 'elevated' or filled crater floors, and faint crater ejecta blankets. Channel floor shows some evidence of streamlining. Slumps and suturelike grooves mark the channel banks. Possible lineations related to superposed crater ejecta are seen in the upper right portion of the mosaic (DAS 8908629, 8908699, 8908769, 8908839). 


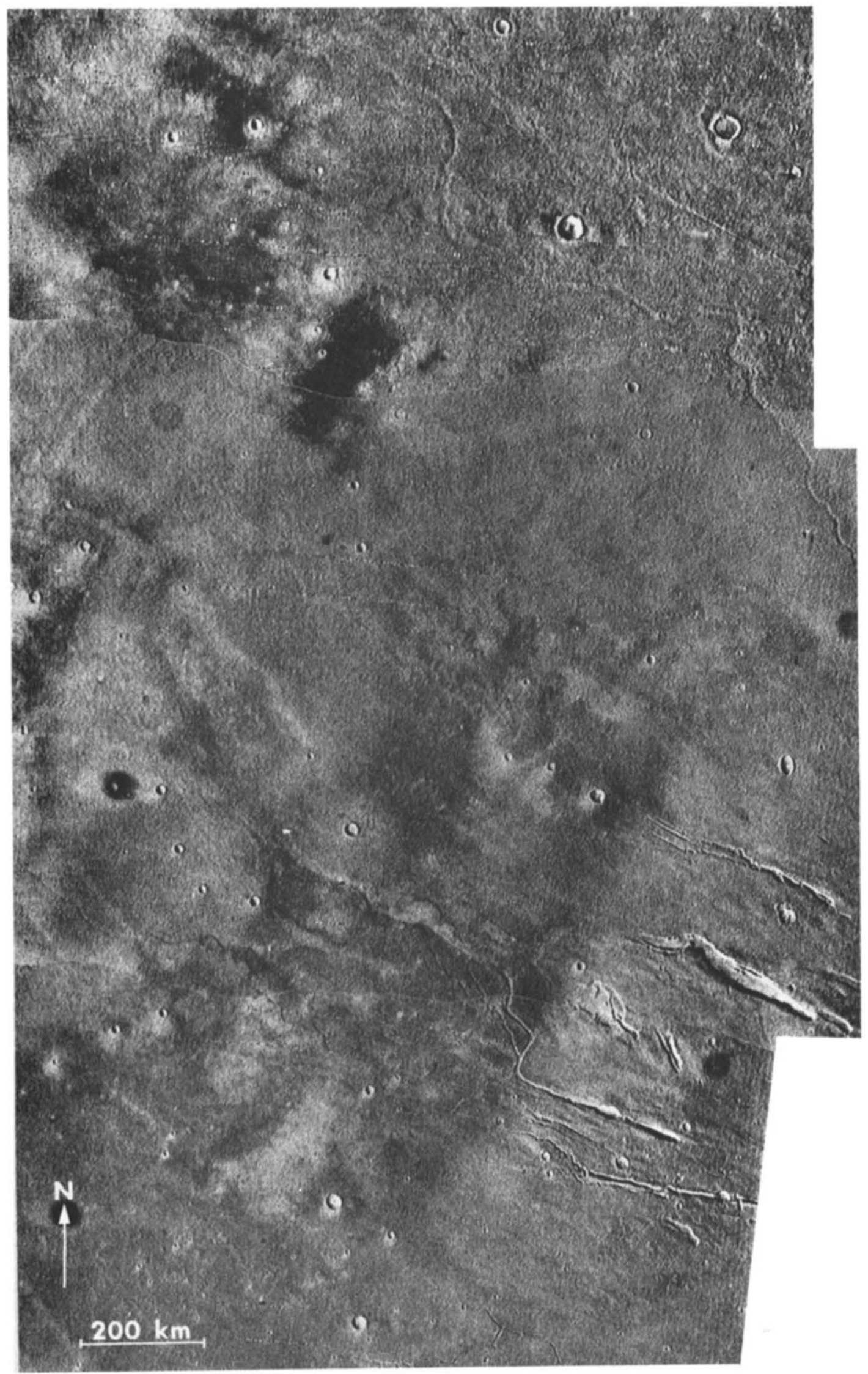

Fig. $10 a$. Unnamed channels in Elysium $\left(225^{\circ} \mathrm{W}, 30^{\circ}-35^{\circ} \mathrm{N}\right)$ : Mariner 9 A frame photomosaic showing the Elysium channel systems west of the Elysium volcanoes. The large channellike forms were interpreted as volcano/tectonic depressions of endogenic orıgin by Sharp and Malin [1975]. Light areas appear moderately to heavily mantled: dark areas seem relatively unmantled (DAS 7579568, 7579708, 8910834). 


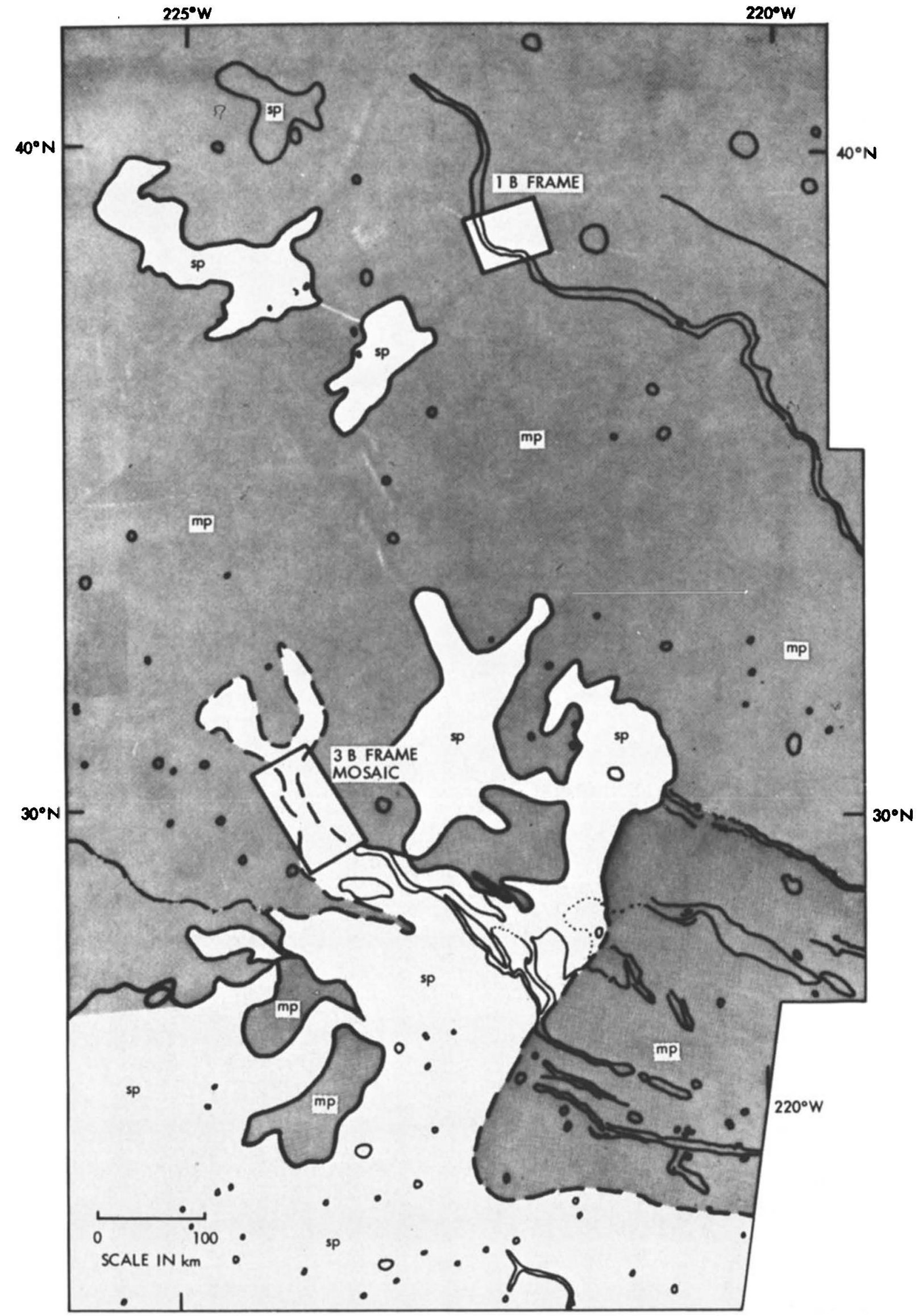

Fig. 10b. Unnamed channels in Elysium $\left(225^{\circ} \mathrm{W}, 30^{\circ}-35^{\circ} \mathrm{N}\right)$ : sketch map of Elysium channels. Shaded area represents areas of subdued, mantled appearance (designated $\mathrm{mp}$ for mantled plains). Two areas covered by $\mathbf{B}$ frames are marked. (Note that both are within mantled regions, although they have been left clear for greater visibility.) 

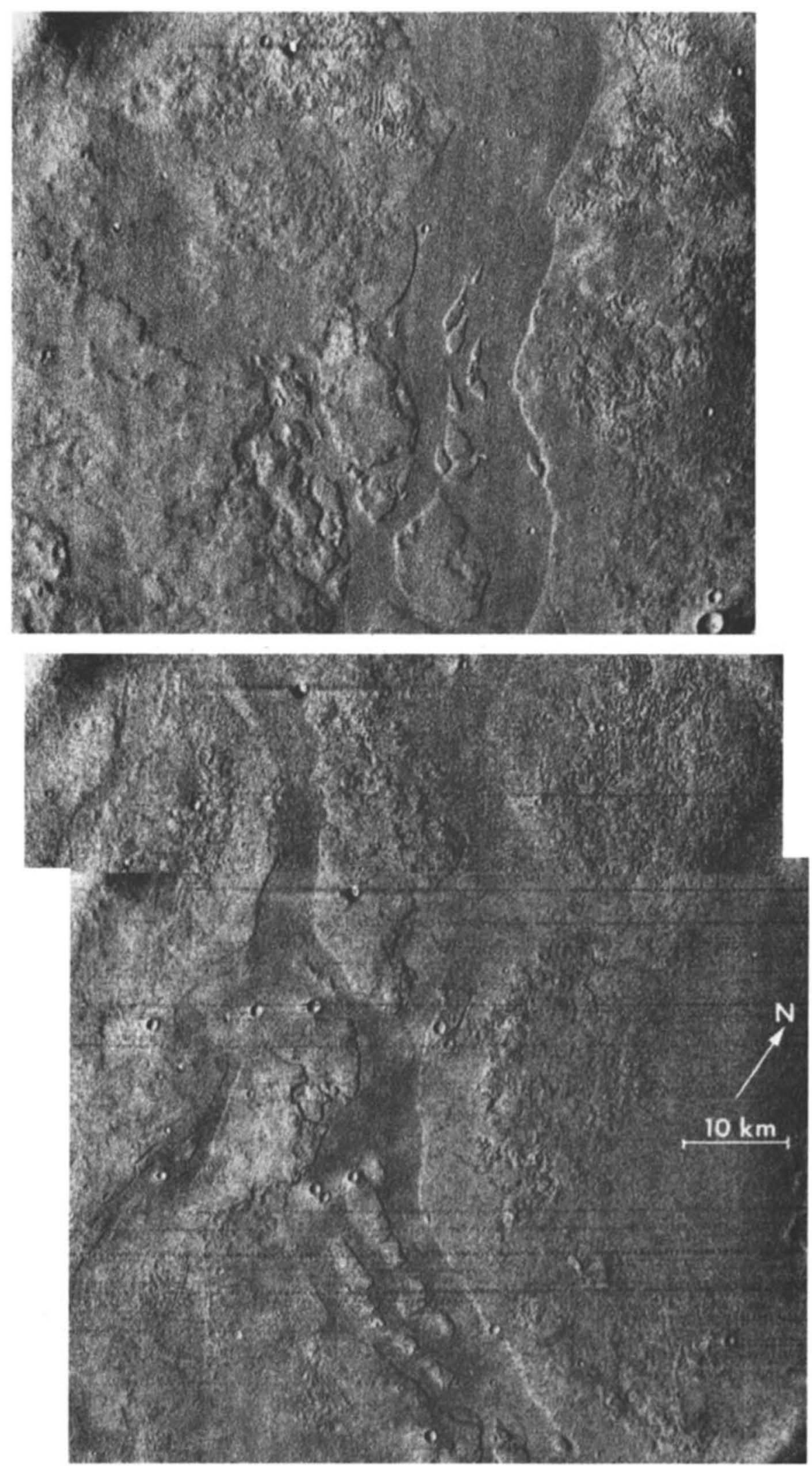

Fig. IIa

Fig 11. B frames of the unnamed channels in Elysium. (a) Two high-resolution frames and one partial almost form a complete photomosarc (DAS 8910729 (1op), 10313809, 10313879). Note the shallow appearance of the channel (large width to depth ratio), the rough texture of the surrounding terrain, and the large number of craters superposed on the channel. Also note streamlined as well as rectilinear islands $(b)$ Single B frame showing mantled texture of plains and subdued nature of Elysium channels. The proposed explanation for the phenomena seen here is that the channels and surrounding terrain are covered by a blanket of weakly consolidated material (possibly a tuff) presently being eroded (DAS 8910869). 


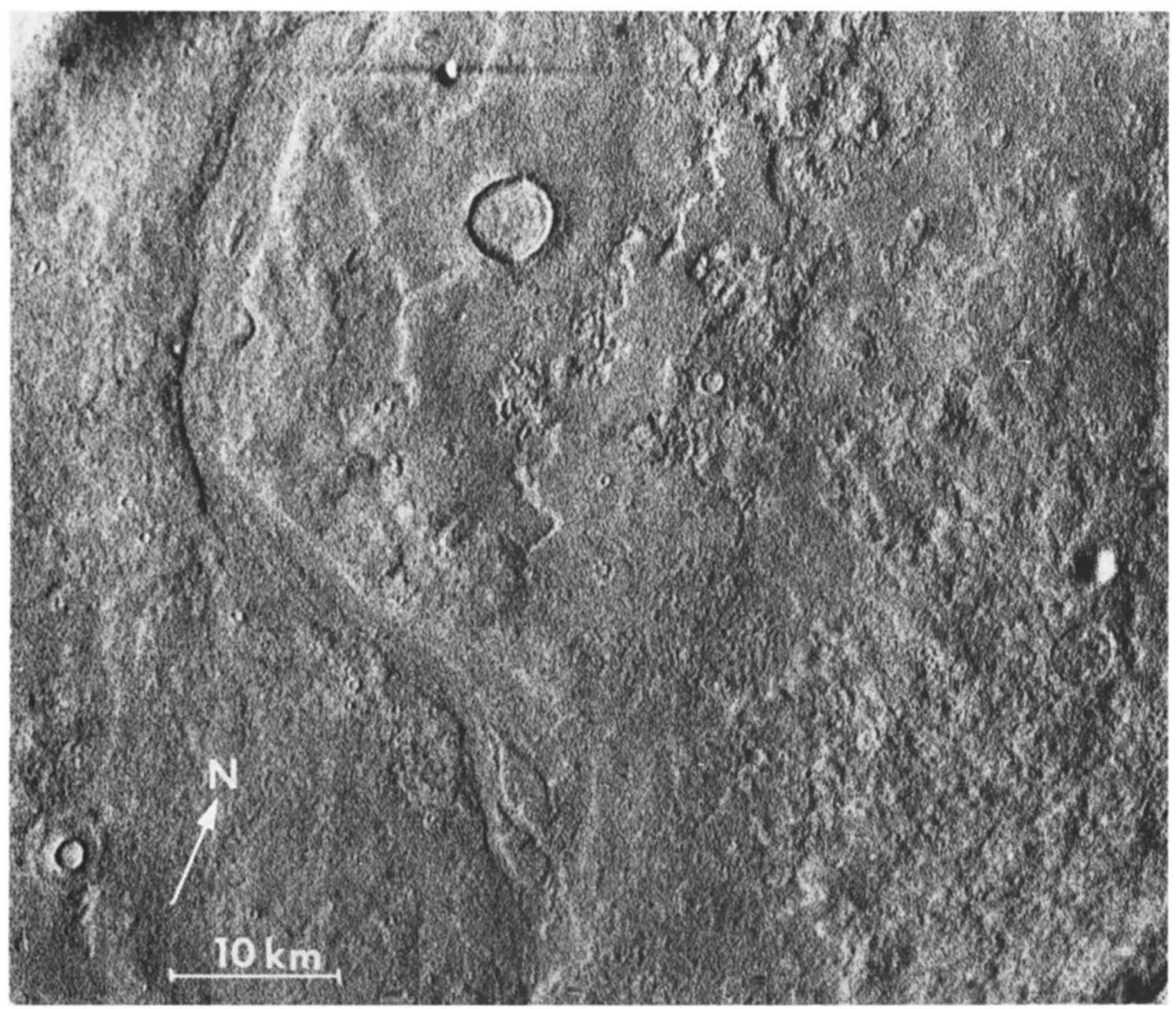

Fig. $11 b$ 


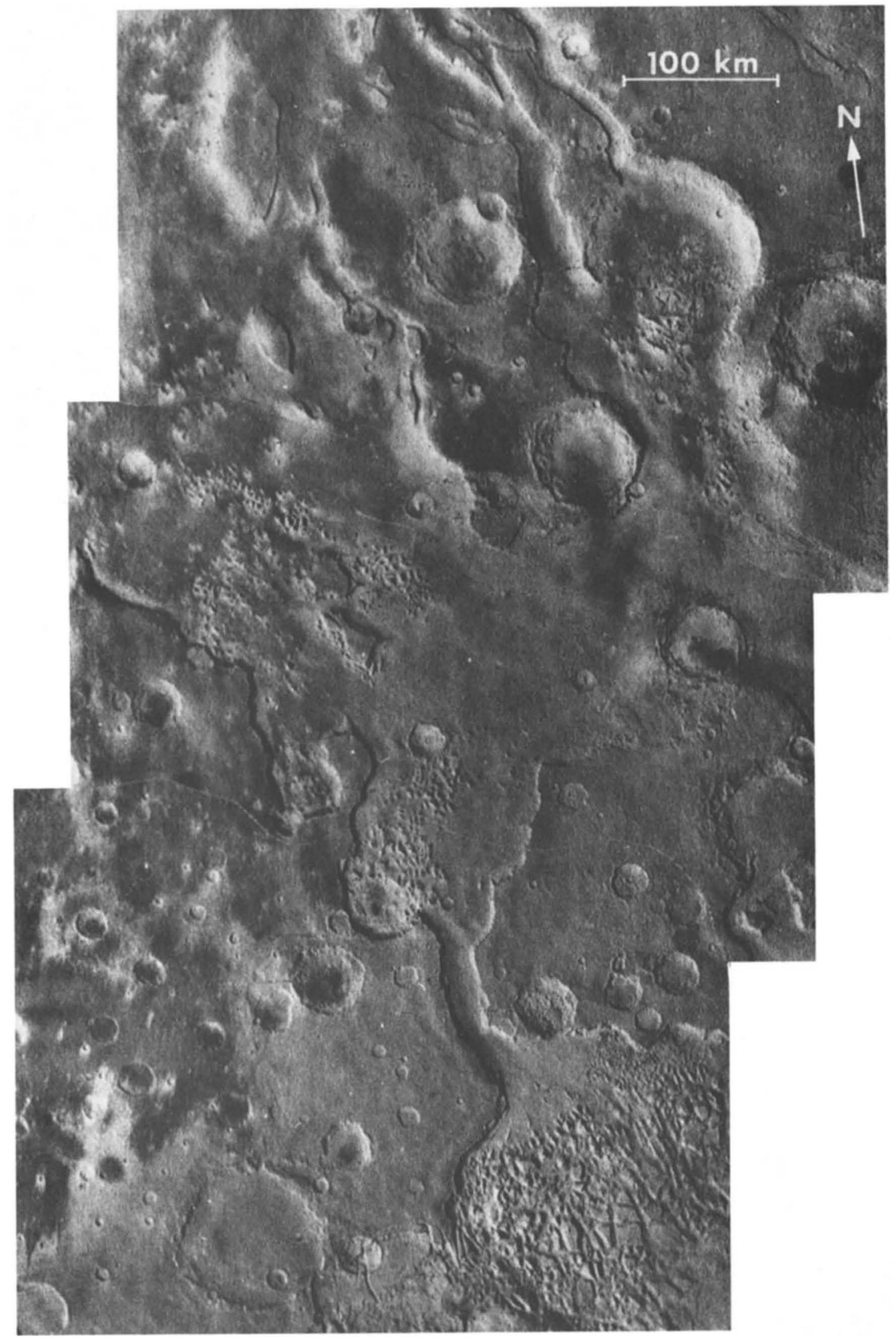

Fig. 12. Tiu and Simud valles: chaotic terrain $\left(34^{\circ} \mathrm{W}, 5^{\circ}-10^{\circ} \mathrm{N}\right)$. Mariner 9 A frame photomosaic of chaotic terrain and associated channels. Note the large number of craters superposed on the floor of the chaotic terrain/channels. Chaos appears to develop within craters with greater ease than within the surrounding intercrater plains. Many areas show a progressive disintegration of landscape, from smooth, unaltered terrain, through a structurally controlled fractured zone, to areas of progressively greater fracturing and landform degradation. A resistant cap rock may promote the visual appearance by fracturing as unconsolidated materials are removed from beneath. Many craters appear to be encountered tangentially by the chaotic terrain and the channels. Some craters appear resistant to the erosional mechanism (DAS $7686808,7686878,7686948)$. 


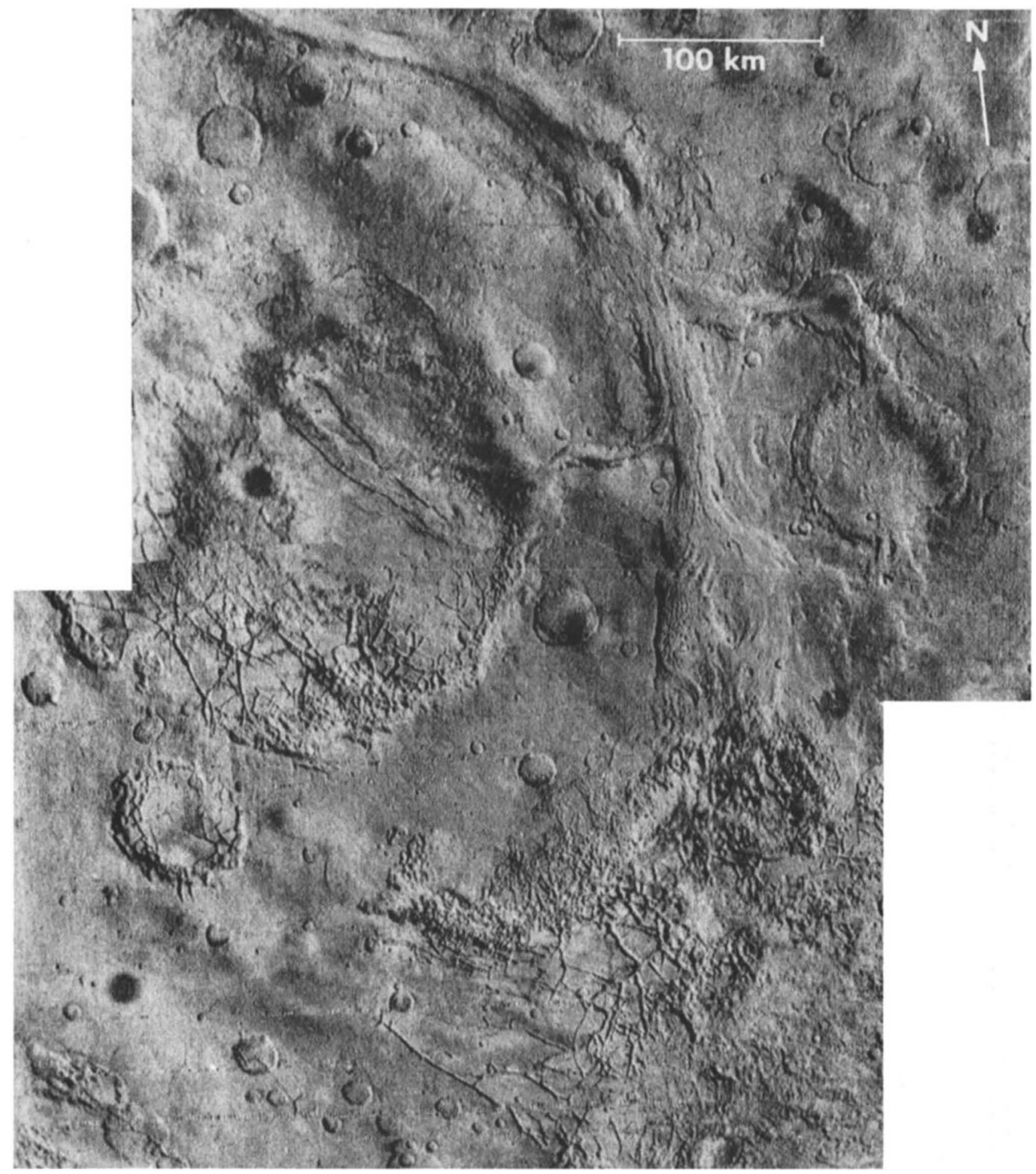

Fig. 13. Ares Channel and associated chaotıc terrain $\left(20^{\circ} \mathrm{W}, 7^{\circ} \mathrm{N}\right)$. Mariner 9 frames show two forms of chaotic terrain in association with the largest of martian channels, Ares Vallis. South of the channel is an irregular region of chaos; west of the channel is a circular region, occupying the interior of what may be a large $(\sim 200 \mathrm{~km})$ crater. Note that the Ares channel breaches head-on two craters immediately west of the main branch of the channel (DAS 7830518, 7830588). 


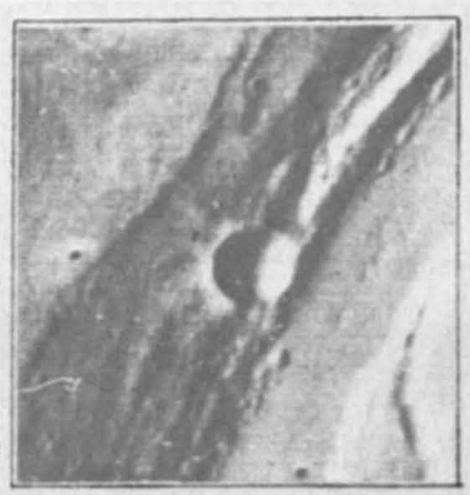

A

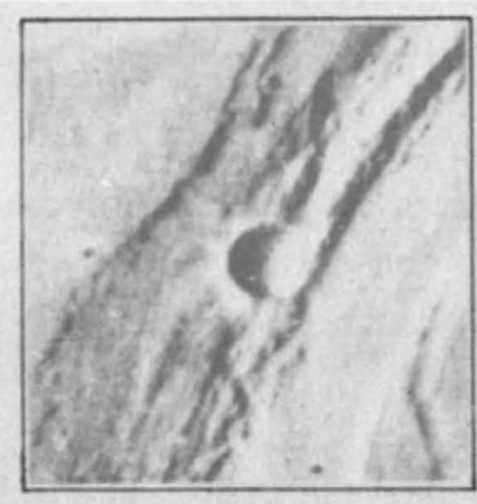

B

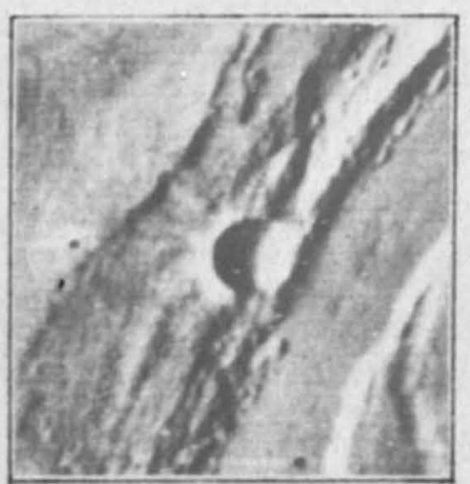

C

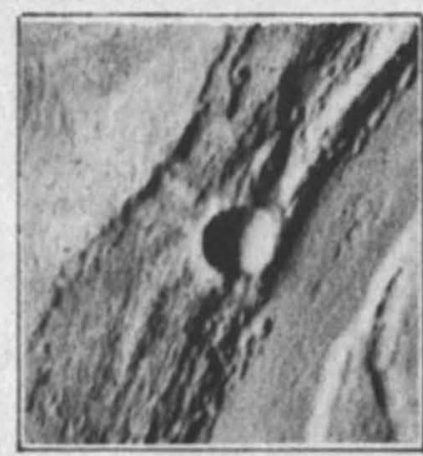

D

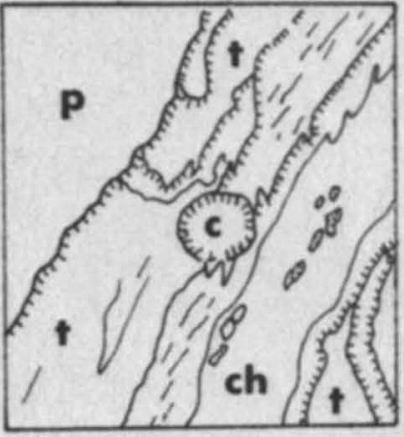

E

Fig. 14. Crater superposed on Mangala Vallis. Crater cited by Hartmann [1974] as evidence for recent flow of material within Mangala channel. Each image represents a portion of DAS 12499790 from line 350 to line 600 , sample 500 to sample 720. Parts $a, b$, and $c$ have undergone Mariner 9 standard processing, presenting a shading-corrected, vertically high-passfiltered, and horizontally high-pass-filtered image, respectively. The crater appears polygonal and is apparently rayed on the left. Part $d$ presents a specially processed image, the high-frequency features boosted through the use of a modulation transfer function related restoration filter. The crater no longer appears polygonal, and the rays are resolved as terrace benches. Part $e$ is a sketch map of the area, where ' $p$ ' stands for plains, ' $t$ ' for terraced channel walls, 'ch' for channel floor, and 'c' for crater.

evidence for recent channel activity has been found. This supports the assertion of Sharp and Malin [1975] that the channels reflect an ancient period in martian history separated from the present by billions of years. The temporal association of chaotic and fretted terrain, areas of lithospheric seepage, the channels, and the intercrater plains unit suggest possible connections exist between the processes which formed these landforms.

Acknowledgments. This paper represents the second of three works comprising my doctoral dissertation at the California Institute of Technology (Caltech). I am pleased to acknowledge the guidance, support, and intellectual stimulation which Bruce Murray and Robert Sharp have given me throughout my years at Caltech. The assistance of G. Edward Danielson, D. Lynn, and J. Soha in providing access to facilities of the Jet Propulsion Laboratory (JPL) was instrumental to this work. Mariner 9 photographs were processed at the Image Processing Laboratory at JPL. I am grateful to JGR reviewers James Cutts and Laurence Soderblom for their helpful comments. This research was supported in part by National Aeronautics and Space Administration grants NGR 05-002-117 and NGR 05-002-305. Contribution 2594, Division of Geological and Planetary Sciences, California Institute of Technology, Pasadena.

\section{REFERENCES}

Arvidson, R. E., Morphologic classification of martian craters and some implications, Icarus, 22, 264-27I, 1974.
Carr, M. H., H. Masursky, and R. S. Saunders, A generalized geologic map of Mars, J. Geophys. Res., 78, 4031-4036, 1973.

Chapman, C. R., Cratering on Mars, 1, Cratering and obliteration history, Icarus, 22, 264-27I, 1974.

Hartmann, W. K., Martian cratering, 4, Mariner 9 initial analysis of cratering chronology, J. Geophys. Res., 78, 4096-4116, 1973.

Hartmann, W. K., Geological observations of martian arroyos, $J$. Geophys. Res., 79, 3951-3957, 1974.

Jones, K. L., Evidence for an episode of martian crater obliteration intermediate in martian history, J. Geophys. Res., 79, 3917-3932, 1974.

Malin, M. C., Lunar red spots: Possible pre-mare materials, Earth Planet. Sci. Lett., 21, 331-341, 1974.

Malin, M. C. Investigation of surface features of the planet Mars, Ph.D. Thesis, Calif. Inst. of Technol., Pasadena, 1976.

McCauley, J. F., M. H. Carr, J. A. Cutts, W. K. Hartmann, H. Masursky, D. J. Milton, R. P. Sharp, and D. E. Wilhelms, Preliminary Mariner 9 report on the geology of Mars, Icarus, 17, 289-327, 1972.

Masursky, H., An overview of geologic results from Mariner 9, J. Geophys. Res., 78, 4009-4030, 1973.

Milton, D. J., Water and processes of degradation in the martian landscape, J. Geophys. Res., 78, 4037-4047, 1973.

Sagan, C., O. B. Toon, and P. J. Gierasch, Climatic change on Mars, Science, 18I, 1045-1049, 1973.

Sharp, R. P., Mars: Chaotic and fretted terrains, J. Geophys. Res., 78, 4073-4083, 1973

Sharp, R. P., and M. C. Malin, Channels on Mars, Geol. Soc. Amer. Bull., 86, 593-609, 1975. 
Soderblom, L. A., T. J. Kreidler, and H. Masursky, Latitudinal distribution of a debris mantle on the martian surface, J. Geophys. Res., $78,4117-4122,1973$

Soderblom, L. A., C. D. Condit, R. A. West, B. M. Herman, and T. J. Kreidler, Martian planetwide crater distributions: Implications for geologic history and surface processes, Icarus, 22, 239-263, 1974.

Ward, W. R., Large-scale variations in the obliquity of Mars, Science. 181, 260-262, 1973.
Ward, W. R., Climatic variations on Mars, 1, Astronomical theory of insolation, J. Geophys. Res.. 79, 3375-3386, 1974.

Wilhelms, D. E., Comparison of martian and lunar geologic provinces, J. Geophys. Res., 79, 3933-3941, 1974.

(Received October 23, 1975;

revised February 25, 1976;

accepted March 2, 1976.) 